\title{
Parental Investment: How an Equity Motive Can Produce Inequality
}

\author{
Ralph Hertwig \\ Columbia University and \\ Max Planck Institute for Human Development \\ Frank J. Sulloway \\ University of California, Berkeley
}

\author{
Jennifer Nerissa Davis \\ Humboldt University
}

\begin{abstract}
The equity heuristic is a decision rule specifying that parents should attempt to subdivide resources more or less equally among their children. This investment rule coincides with the prescription from optimality models in economics and biology in cases in which expected future return for each offspring is equal. In this article, the authors present a counterintuitive implication of the equity heuristic: Whereas an equity motive produces a fair distribution at any given point in time, it yields a cumulative distribution of investments that is unequal. The authors test this analytical observation against evidence reported in studies exploring parental investment and show how the equity heuristic can provide an explanation of why the literature reports a diversity of birth order effects with respect to parental resource allocation.
\end{abstract}

Israel loved Joseph more than all his children, because he was the son of his old age: and he made him a coat of many colours. And when his brethren saw that their father loved him more than his brethren, they hated him, and they could not speak peaceably unto him.

$$
\text { —Book of Genesis, King James Bible }
$$

The belief that one's brother or sister is favored by one's parents has been portrayed as the key cause of antagonistic sibling relationships throughout history, not just in the story of Joseph, but in numerous other places in the Bible (e.g., in the stories of Cain and Abel and Jacob and Esau). Similar stories about parental favoritism and sibling jealousy are found in Shakespeare's plays (e.g., in Richard III and King Lear) and in the writings of John Steinbeck (e.g., East of Eden), to name just a few other literary instances. The consequences of this belief, whether mistaken or correct, have often been destructive and tragic. Is this theme so pervasive throughout human history because parental favoritism is pervasive too, or is such favoritism merely a misperception on the part of jealous siblings? Or, paradoxically, could such inequality actually be the inevitable consequence of parental attempts to treat their children equally?

Ralph Hertwig, Department of Psychology, Columbia University and Center for Adaptive Behavior and Cognition, Max Planck Institute for Human Development, Berlin, Germany; Jennifer Nerissa Davis, Institute of Theoretical Biology, Humboldt University, Berlin, Germany; Frank J. Sulloway, Department of Psychology, University of California, Berkeley.

This work was completed while Ralph Hertwig was a visiting scholar at Columbia University. We thank the Deutsche Forschungsgemeinschaft for its financial support of Ralph Hertwig with Grant He 2768/6-1 and Clark H. Barrett, Harald Euler, Alexandra M. Freund, Monique Borgerhoff Mulder, Andreas Ortmann, and Eckart Voland for many helpful comments.

Correspondence concerning this article should be addressed to Ralph Hertwig, Center for Adaptive Behavior and Cognition, Max Planck Institute for Human Development, Lentzeallee 94, 14195 Berlin, Germany. E-mail: hertwig@mpib-berlin.mpg.de
This last, counterintuitive possibility is the focus of this article. Leaving aside the issue of sibling rivalry (and siblings' perception of parental behavior), we direct our attention to the major factor thought to cause it: parental favoritism, or the unequal distribution of parental investment. On the basis of simple arithmetic computations, we argue that even if a parent's investment heuristic is guided by a motive of equity, such a motive could still produce inequality in the cumulative distribution of resources among children of different birth ranks. ${ }^{1}$ In other words, we argue that even if parents attempt to invest equally, the amount of resources each child receives may still, as a consequence of birth order, be unequal.

Before we explicate this argument, let us address one likely misconception. In analyzing the consequences of equal resource allocation, we do not mean to suggest that factors that have been found to affect the allocation of parental resources are irrelevant (such as paternity uncertainty, children's temperament, or parenting experience; see e.g., Geary, 2000; Neiderhiser, Reiss, Hetherington, \& Plomin, 1999). Moreover, we also do not intend to imply that parents are truly and strictly egalitarian no matter what their children's needs, abilities, social, and economic prospects are. Such claims would be naive. The aim of our analysis is, instead, to highlight an overlooked possibility-namely, that those parents who cherish a motive of equity may, all things being equal, still end up biasing investment for reasons due to the counterintuitive consequences of the equity heuristic.

\footnotetext{
${ }^{1}$ In research on distributional justice, the terms equity and equality describe two distinct allocation principles (Deutsch, 1975). In contrast, we use the terms equity and equality interchangeably, which accords with the most general definition of equity in the English language (namely, the quality of being equal or fair), a meaning that is derived etymologically from the Latin aquus, meaning "equal, fair" (Simpson \& Weiner, 1989, p. 358 ).
} 
This article consists of four sections: a brief exploration of how parents ought to invest in their offspring according to evolutionary biologists and economists, an exposition and analysis of the equity heuristic, a test of predictions of the equity heuristic against available evidence in the literature, and a general discussion of alternative explanations for birth order effects and the developmental implications of the equity heuristic.

\section{How to Divide Parental Resources?}

\section{Answers From Evolutionary Biology}

According to Trivers (1972), parental investment is any investment by the parent in an individual offspring that increases the offspring's chance of survival (and the offspring's reproductive potential) at the cost of the parent's ability to invest in other offspring. The most important aspects of parental investment for our purposes are that (a) it is something that parents have in only a limited supply and that (b) when faced with the task of raising offspring born at different times, investment in one offspring generally detracts from resources available for other offspring that are still under parental care. How, then, should parents distribute their limited resources among their offspring? This is not only a very difficult but also a very important evolutionary problem for parents to solve, and we expect that natural selection has endowed them with decision-making mechanisms that provide them with good solutions. But what constitutes a good solution?

According to evolutionary theory, in particular the work of Trivers (1974), parents and children often disagree about what is a good solution for the distribution of parental resources. Such disagreement hinges on the joint influence of two factors: the marginal value of each unit of resource to each child and the degree of relatedness. According to this logic, reasoned by Trivers from Hamilton's (1964a, 1964b) inclusive fitness principle, children favor an unequal distribution of parental investment. The key to their bias is the notion of relatedness: A child shares a given gene with itself with a probability of 1.0, but it shares the same gene with a probability of only .5 with a sibling. For this reason, a child is expected to strive to monopolize a unit of resource unless the marginal value of consuming an extra unit of resource is less than the benefit, scaled by degree of relatedness, of donating the resource to its relative. ${ }^{2}$ Parents, in contrast, share a given gene with each of their offspring with a probability of .5. Thus, they strive to divide a unit of resource equally unless the marginal benefit resulting for this unit is larger for one child compared with another.

Daly and Wilson (1988) have provided the following illustration of children and parents' conflicting interests. Suppose a mother comes home from a day of gathering with two food items to give her children, A and B. Both children have equal survival prospects and reproductive potential. With food and many other resources, there are diminishing returns associated with increased consumption. That is, the first unit of food, for example, may prevent the child from starving, whereas the second unit of food may just make the child a little bit more full. Assume that both siblings' consumption of the two food items follow the same marginal utility curve-that is, the first item would raise their survival prospects (and thus potentially add to their reproductive potential) by four units, and the second item of food would raise it an additional three units. Parent-offspring conflict arises because, from the mother's perspective, the ideal allocation would be to give one unit of food to Sibling A and one to Sibling B, thus reaping a net benefit of eight units of increase. By contrast, if one sibling monopolized all the food, the gain would only be seven units (four for the first food item plus three for the second food item). Thus, from the mother's perspective an equal allocation between her children would yield the best outcome, whereas from each sibling's perspective the ideal allocation is to monopolize all the food (the boundary condition being specified by Hamilton's 1964a, 1964b, rule; see Footnote 2).

Evolutionary biologists typically answer the question of what constitutes a good solution to the problem of how to allocate parental resources not by designing specific mechanisms (e.g., decision heuristics) but by identifying and modeling the selection pressures that are expected to have shaped them. Following this approach, any kind of decision heuristic that satisfies the constraints of, for instance, Hamilton's (1964a, 1964b) rule can be selected for, and decision rules that, on average, do a better job of satisfying this rule would benefit from a selective advantage.

\section{Answers From Economics}

In an economic analysis of how rational parents should optimally distribute investment among their children, Becker (1991) assumed that parents try to maximize total child quality as defined by the sum of their children's adult wealth. The quality of a child - that is, the parental payoff-is assumed to be a function of the resources invested in the child, the child's own skills and abilities, and any extra income the child might earn as an adult through sheer luck. Becker's analysis suggests that, as long as the payoff curve is the same for all children, parents should distribute investment equally among them. If, however, the abilities of some children are such that increasing the amount of investment in them relative to their siblings leads to greater payoff to parents in overall child quality, they should bias investment in favor of those children (Becker \& Tomes, 1976, 1986).

Although Becker's (1991) analysis is a celebrated case of extending economic theory beyond its usual domain of application, it has the character of an "as if" approach (Elster, 1997) insofar as it validates the utility-maximizing model by the accuracy of outcome predictions rather than by the psychological plausibility of the implied processes. In fact, if one were to try to use these prescribed investment policies as decision mechanisms, their intractability would quickly become apparent. To use them as such, one has to assume that parents have some means of calculating the effects of each individual unit of investment on the future payoff they expect to gain from each child, compounded over time for every discrete investment and maximized across all children. To be able to do this, parents not only need to keep track of the effect of every act of current and potential future investment on the eventual outcome of each child (a problem of combinatorial explosion) but they also

\footnotetext{
${ }^{2}$ According to Hamilton's rule, a gene (e.g., for altruism) can evolve and remain stable in a population if $r B>C$. In this formulation, $B$ is the benefit to the recipient (e.g., a sibling) of an altruistic act (e.g., food sharing), $r$ is the coefficient of relatedness between the altruist and the recipient (i.e., the probability of sharing a given gene by descent), and $C$ is the cost to the altruist.
} 
need to convert the effects of such varied types of investment as piano lessons, doctors appointments, and meals prepared into a common currency.

The problem of how actual parents make investment decisions cannot easily be solved by optimization. The range of possibilities that must be taken into account is far too vast and the number of required calculations too high. Nevertheless, the fact that it is impossible for parents to calculate the optimal investment strategy directly does not mean that parents are not using very good, albeit much simpler, decision strategies (see Chase, Hertwig, \& Gigerenzer, 1998; Gigerenzer, Todd, \& the ABC Research Group, 1999). What sort of decision rules could parents use? At an abstract level, the problem faced by human parents trying to figure out how to divide investment among multiple children is identical to the problem faced by any species in which multiple dependent offspring of differing ages are raised simultaneously. Such circumstances are relatively common in birds. Davis and colleagues (Davis \& Todd, 1999; Davis, Todd, \& Bullock, 1999) modeled the success of a variety of potential parental investment decision rules in one species, the Western bluebird. These rules specify momentto-moment parental decisions about which chick in the nest to feed (the main currency of divisible parental investment in birds). The authors found that the success of different rules is highly dependent on the amount of resources available to parents. Specifically, the less parents have, the more biased they ought to be in their distribution of investment. Parents faced with extremely poor resources ought to invest heavily, or even exclusively, in a single chick, ignoring the others. As resources become more plentiful, parents do best by becoming gradually more egalitarian. Parents with plentiful resources, defined in this case as enough resources to successfully raise all of the chicks in the nest to adulthood, do best by using decision rules that divide these resources equally among all chicks. At a more general level, one can conclude that the degree to which parents divide current investment unequally among offspring is a function of the amount of resources available to them.

It is important to note that in this avian model, and in evolutionary biology in general, divisible parental investment is primarily understood in terms of provisioning (Clutton-Brock, 1991). Whereas this assumption is true of humans as well, it does not capture the full extent of human parental care. In particular, this assumption misses all the things that parents provide, such as education, sporting activities, or music lessons, that are seen, from an economic perspective, as investment in children's economic capital. From an evolutionary perspective, such behavior has no obvious, direct effects on survivorship, and thereby requires additional explanation. Why would parental motivation to invest include such considerations? One likely answer is that such motivation reflects an evolved disposition to invest in children's later social competitiveness, something that could evolve if social competitiveness covaried with reproductive outcomes and inversely with mortality risks, which it seems to (Boone \& Kessler, 1999; for additional discussion of this and related issues, see Geary, 2000; Geary \& Flinn, 2001).

Another important point is that the parent birds in the previous model faced extreme resource shortages, which were so dire that it was impossible for all of the chicks to survive. As soon as there were enough resources to keep them all alive, egalitarian division rules did the best. If one assumes that human parents typically do have enough resources available to them to raise all of their children to adulthood, especially in modern Western societies, then this assumption leads to the expectation that human parents may use a decision rule that divides investment equally among all of their children. ${ }^{3}$

\section{The Equity Heuristic}

This decision rule is what we call the equity heuristic. The rule specifies that parents attempt to split resources equally among all children. Is there any evidence that parents use the equity heuristic? Historically, there is. In the Italian city-states of medieval Europe, wealth was mostly based on financial speculation and could be won or lost in a single generation. In this situation, "given the role that chance plays in the survival of any lineage, an equal distribution of parental investment reduces the risk that family lineage will go extinct" (Sulloway, 1996, p. 65). In fact, parents wisely hedged their genetic bets, distributing their assets equally among their children (Herlihy, 1973). But what about contemporary parents?

If parents are using the equity heuristic, this should be reflected both in parental self-reports and behavior. There is a body of evidence that suggests they do. For instance, Schooler (1972) discussed several studies from the 1960s that examine parents' reports of their treatment of children of different birth ranks and concluded that there were no differences in treatment by birth rank in the mid-1960s. According to Daniels, Dunn, Furstenberg, and Plomin (1985), this conclusion still held true in the 1980s. Zervas and Sherman (1994) argued that "as members of an egalitarian society, Americans typically espouse equal treatment of children by parents" (p. 31). Others have shown that children themselves also believe that they receive equal treatment (e.g., Plomin \& Daniels, 1987). Measurement of actual parental behavior seems to validate these perceptions, as parents have been observed to be relatively egalitarian (Caldwell \& Bradley, 1984; Vandell \& Beckwith, 1989).

The observation of egalitarian treatment has not remained unchallenged. For instance, one study by Dunn and McGuire (1994) reported that only one mother in three says that she gives similar attention to each child. In other studies, children themselves have reported perceived differences in the treatment they and their sibling receive from parents (e.g., Daniels \& Plomin, 1985; Koch, 1960), and still other researchers have demonstrated that parents

\footnotetext{
${ }^{3}$ One objection that has been raised to this conclusion is that Davis et al.'s (1999) analysis of birds cannot easily be extended to humans for two reasons: Birds are born in clutches of approximately the same age and secondly, they have a far more limited period of parental investment than humans. It is important to realize that in species with asynchronous hatching, the chicks in the nest are not the same age, albeit age differences are small and measured in days. Baby songbirds grow very fast, going from newly hatched to fledged in a matter of 2 to 3 weeks, and an age difference of as little as a day does make a significant difference in the size and developmental stage of a chick. For this reason, one may reasonably argue that bird parents do, in fact, face an ecological situation similar to that of human parents. This situation is unlike that faced by most other mammals, among whom young are typically born and raised simultaneously rather than at intervals. Finally, that the period of investment is short simply makes birds an easier model for study than humans.
} 
consistently direct more behaviors toward younger rather than older siblings (Brody \& Stoneman, 1994; Maccoby \& Martin, 1983).

Although this mixed evidence suggests that at least some parents under some circumstances appear to split the resources equally among all children, there is one key finding that seems to challenge even this cautious conclusion. Does the very existence of widely documented birth order effects not exclude the equity heuristic as a plausible decision rule for how real parents make their decisions? Our answer is no, for at least two reasons.

\section{How the Equity Heuristic Creates Inequality}

One reason is that even in the face of actual equality, treatment is still perceived as unequal. Vandell and Beckwith (1989) made this observation in their study of mothers' behavior toward twins. Each twin was randomly assigned to an observer who rated the treatment received by that twin. Although there was remarkable consistency in both observers' reports of maternal behavior, during the course of the study each observer came to identify with "their" twin and reported thinking that the mothers preferred the other twin. Siblings' perception of unequal treatment might similarly be driven by sibling and parents' disparate understanding of equality. As described earlier, offspring, unlike parents, generally prefer to acquire more of any scarce resource than a sibling receives (Daly \& Wilson, 1988; Hamilton, 1964a, 1964b). If birth order effects are more a function of the perceived than the actual resource distribution, then siblings may see themselves as being treated unfairly even when there is an equitable distribution.

Perhaps the most interesting reason why birth order effects may not be contrary to the application of the equity heuristic is that birth order effects can actually be a consequence of parental egalitarianism. That is, even if at any given point in time parental investment is distributed according to the equity heuristic, cumulative investment may still end up being unequal. How can this occur? Let us assume that a family has $n$ children, all of whom are born at equal time intervals. In addition, we assume that the entire growth period can be divided into a number of time periods of equal length and that parents invest in a child during a finite number of periods. We assume that the parents' resources are limited, that is, increasing the number of children does not increase the total amount of investment they can provide. We also assume that parents use the equity heuristic, splitting resources equally among children (i.e., for $n$ children, a proportional split means that each offspring receives $1 / n$ of the total resources). As a consequence, the amount of resources obtained by a child in any given period is a function of the number of siblings it has during this same time period.

In the upper part of Figure 1, we present the proportion of resources obtained for a child in each of several birth ranks, in sibship sizes ranging from one to three, and across four periods of growth ("years"). The bars in the lower part of Figure 1 show the cumulative resource distribution for children in an only-child, a two-child, and a three-child family. Several patterns emerge from this figure. Not surprisingly, the larger the family size, the smaller the amount of received resources per child. An only child receives the most resources, followed by children in a two-child family, whereas children in a three-child family receive the least. In terms of cumulative investment (expressed as a percentage of the total

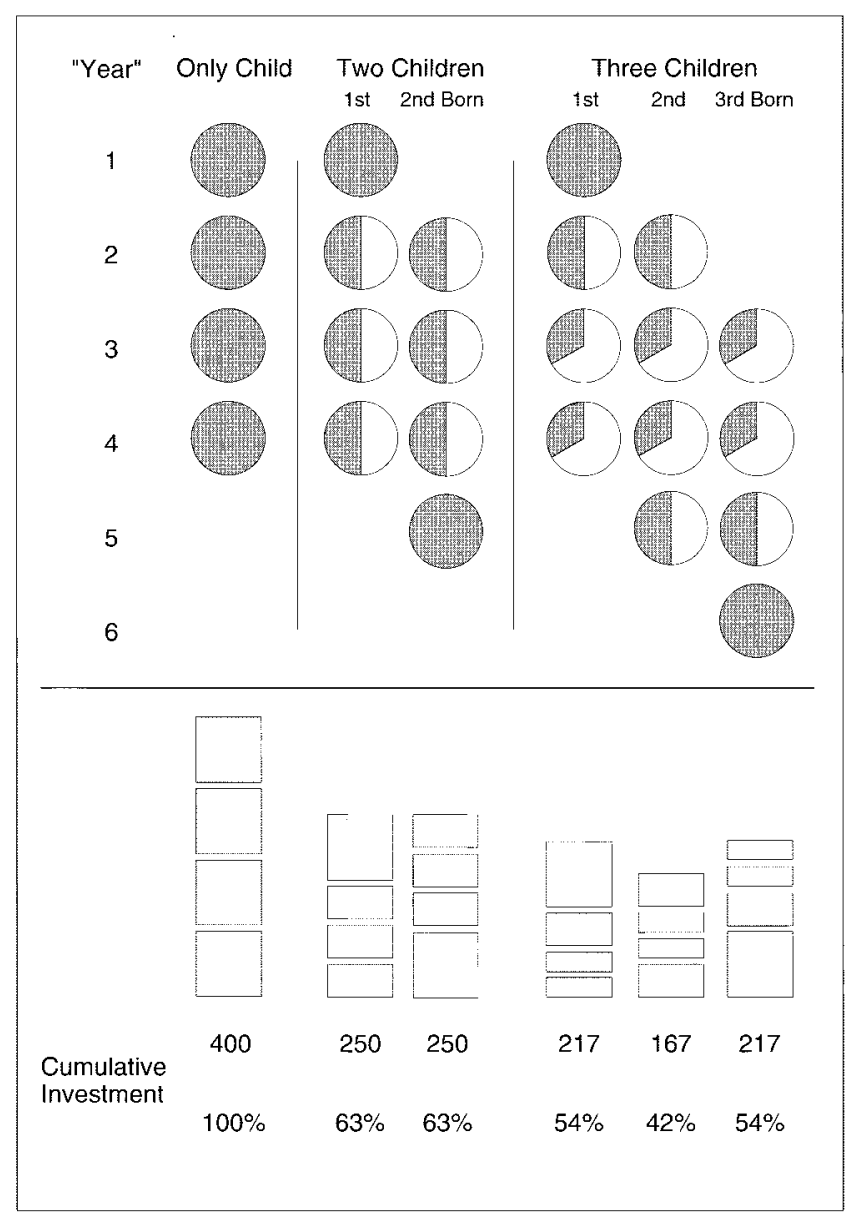

Figure 1. Spheres in the upper part of the figure represent resource allocation according to the equity heuristic as a function of birth rank in families with one, two, and three children. The bars in the lower part show the absolute and relative (i.e., calculated as a proportion of that for an only child) cumulative investments across four growth periods ("years").

resources the only child receives) children in a two-child family receive $62.5 \%$ each, and children in a three-child family receive $54 \%, 41.5 \%$, and $54 \%$ respectively. There are two surprising patterns in Figure 1. First, despite the application of the equity heuristic, a birth order effect emerges in the three-child family (and not in the two-child family) with respect to the cumulative resource distribution. Second, in this scenario one can actually observe three seemingly contradictory birth order effects, namely, a middleborn, a laterborn, and an earlierborn resource handicap. We describe each handicap in more detail.

Middleborn resource handicap. Despite the fact that resources are equally distributed among children in each year, the cumulative resources (i.e., the total amount of resources received over four periods relative to the amount received by an only child) are not the same for each child in the three-child family. Compared with the middleborn, the firstborn and the lastborn children have an advantage. The reason is simple: Unlike these other siblings, the middle child never has the opportunity to be the only child in the household at any point in its life.

The middleborn resource handicap, however, is only one of three handicaps; to understand the other two, one must first chal- 
lenge a common assumption in utility-maximization models (Becker \& Tomes, 1976; Taubman \& Behrman, 1986), namely, that different resources can be translated into one subdividable commodity. Contrary to this assumption, various authors have argued that real organisms allocate qualitatively different types of parental resources (e.g., Borgerhoff Mulder, 1998; Frank, 1990; McGinley \& Charnov, 1988; Rosenheim, Nonacs, \& Mangel, 1996). Acknowledging the multidimensional nature of parental resources allows one to consider an interesting possibility. Assume that the utility function of a resource (e.g., time) is not constant across a child's growth period but rather that some resources may be more important at an earlier than at a later developmental stage. If this assumption were true, how would it affect the relative advantages or disadvantages of a specific birth rank?

Laterborn resource handicap. Assume that the presence of some resources is most critical when a child is most helpless, that is, at the very beginning of his or her life. One crucial parental currency at this stage may be time spent on child care. If this assumption is true, then the resource environment puts laterborn children at a disadvantage. In their first year, newborns (in both two-child and three-child families) receive different amounts of resources contingent on birth rank: For instance, the firstborn child in a three-child family receives $100 \%$ of these resources, whereas the middle and lastborn child only receive $50 \%$ and $33 \%$ of the resources, respectively (see upper part of Figure 1).

Earlierborn resource handicap. Figure 1 reveals still another potential birth order effect. There may be resources such as an allowance or privileges such as borrowing the car or staying out late that are exclusive to the last years of a child's development. For these resources, the earlierborn children (in both two-child and three-child families) are at disadvantage compared with the lastborn, assuming that such parental resources have some critical value for development.

In sum, despite parental attempts at equality, the equity heuristic shows how three seemingly contradictory birth order effects in the distribution of parental resources can emerge. We suggest that these theoretically predicted birth order effects may help to integrate some of the diverse findings regarding parental resource allocation that exist in the birth order literature. Before we turn to this possibility, however, we ought to clarify the assumptions that underlie our analysis of the equity heuristic.

\section{Underlying Assumptions}

The simple analysis of the equity heuristic depicted in Figure 1 rests on several assumptions. First, we assume that the entire growth period can be divided into a number of intervals of equal length. For simplicity, we label those intervals years. This label is not meant to imply that parents conceive of allocation schedules based on a yearly basis. Rather, the equity heuristic assumes that parents try to distribute their resources fairly among their children during a given arbitrary unit of time. Second, we assume that the parents' resource budget is limited and stable, a reasonable assumption for currencies such as time, attention, and emotional energy. In these cases, new demands, such as the addition of a newborn infant to the family, must be met at the cost of old demands-for example, the time devoted to the newborn's older siblings. In contrast, financial resources are limited but also likely to increase as a function of increasing age of parents. Thus, a new child does not necessarily force parents to decrease their monetary investment in older offspring if the new demand can be compensated by a larger budget or by reallocating resources.

Finally, in Figure 1 we assume that resources are split equally among children. How plausible is this assumption? Although we have described several studies that are consistent with it, we do not mean to suggest that equal splitting of resources is ubiquitously applied regardless of important circumstances such as the family's economic condition or children's age-specific needs (an important issue to which we return in the General Discussion section). Rather, the aim of our analysis is to highlight the possibility that birth order effects can at least in principle arise from parental attempts at equal treatment. In other words, unequal output (i.e., birth order effects) does not require unequal input (e.g., discriminatory parental behavior).

\section{Moderating Circumstances}

Research on the potential effects of birth order has often been criticized for its lack of control of confounding variables (e.g., Ernst \& Angst, 1983). Note the words of Lindert (1977), for instance:

[The] entire literature remains vulnerable to a single line of attack: other important variables have not been held constant, and any correlation between these omitted variables and sibling position ... can yield misleading estimates of the impact of the latter. (p. 199)

The simple analysis displayed in Figure 1 affords us the opportunity to describe how other variables affect the distribution of resources, assuming that parents use the equity heuristic. We focus on three variables frequently mentioned, length of growth period, interbirth interval, and sibship size, and discuss how each variable interacts with the resource handicaps we have identified.

Length of growth period. As shown earlier, the cumulative resources of a middle child are smaller than those of its elder and younger siblings because the middle child lacks the opportunity to be the only child in the household at any time in its life. This handicap, however, is moderated by the length of the growth period. For the sake of argument, assume that a child is mature after eight periods rather than after four periods, as we posit in Figure 1. How does the size of the mature middleborn handicap change? Some simple arithmetic calculations show that in this case the cumulative resources for a three-child family would be $44 \%$, $37 \%$, and $44 \%$ for the firstborn, secondborn, and thirdborn child, respectively (expressed as a percentage of the total resources the only child receives). Thus, compared with the size of the difference between the middle child and its younger and older siblings in Figure 1, the handicap decreases, becoming 7 as opposed to 12 percentage points. The longer the time of parental care, all things being equal, the smaller the middleborn handicap. The reason is that the proportion of the total child-care time, in which the younger and elder siblings benefit by having some period of exclusive attention, becomes smaller.

Interbirth interval. Although dependency may be slightly reduced when compared with that of infants, children's reliance on their parents is certainly not over after the first 3 or 4 years. One way to mitigate a resource allocation dilemma is to avoid or reduce the overlap of sequential offspring. The Ache, hunter-gatherers of eastern Paraguay, are reported to use infanticide as a mechanism to 
increase child spacing (e.g., K. Hill \& Hurtado, 1996). In huntergatherer societies more generally, it has also been suggested that prolonged lactation produces contraceptive amenorrhea for the mother for up to 4 years after the birth of a child (Lee, 1979). In modern society, average interbirth intervals are slightly smaller (3.83 years in a recent survey of 28,562 individuals living predominantly in the United States, Canada, and Europe; Sulloway, 2001b).

How does the amount of overlap affect resource allocation for the middle child? In Figure 2, we plot the cumulative investment for the middle child and the resource handicap as a function of interbirth intervals. Here, we assume a three-child family in which a child is mature after 18 years. (In fact, in hunter-gatherer populations, children are net calorie consumers until they reach their mid- to late teens, Kaplan, Hill, Lancaster, \& Hurtado, 2000.) In addition, we assume that all children are born at equal time intervals and that the intervals can range between 1 and 18 years.

Consistent with Kidwell's (1981) suggestion about the benefits of more "breathing room" (p. 317), middle children (as well as their siblings) receive more resources with longer interbirth intervals. The reason is that, with more spacing between children, the proportion of the total growth period in which each child benefits by having no sibling or only one sibling becomes larger. However-and this is another surprising observation-more resources do not necessarily mean that the middle child is not subject to an increasing resource handicap. In fact, as Figure 2 also shows, the larger the interbirth interval, the bigger the middleborn resource handicap. With larger child spacing, the proportion of the total growth period in which the elder and younger siblings benefit by having some period of exclusive attention becomes larger, and the middle child is increasingly at a disadvantage. However, if the

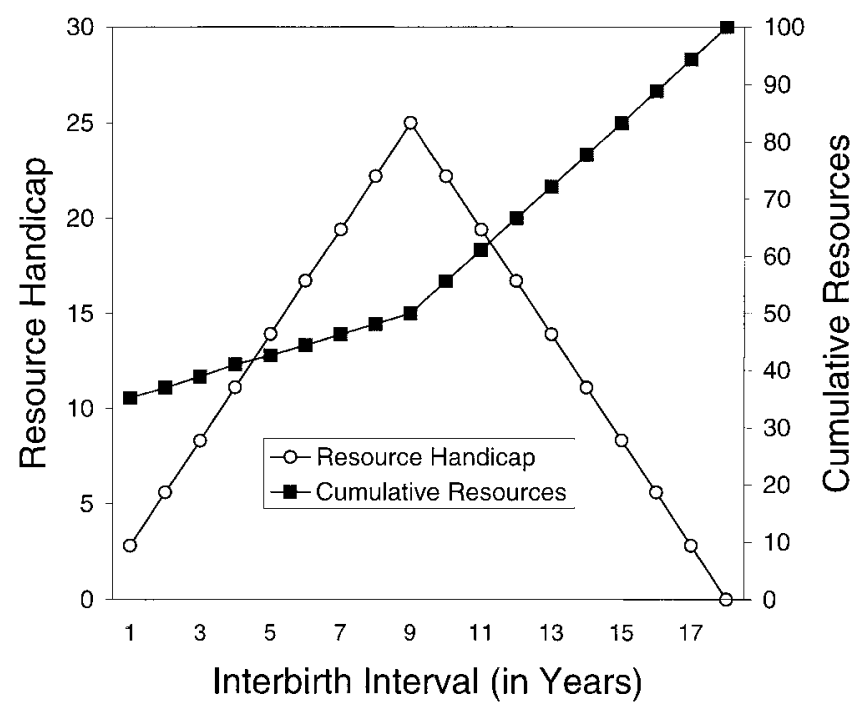

Figure 2. Middleborn resource handicap and amount of cumulative resources as a function of length of interbirth interval (assuming a family of three children and a 18-year growth period). Cumulative investment equals the total amount of investments expressed as a percentage of the total resources the only child receives, and the resource handicap is the difference in cumulative investments for the middle child and the first and lastborn child, respectively. interval exceeds half of the total growth period (here, 9 years), this trend reverses and the handicap becomes increasingly smaller. This is because when the interbirth interval is larger than half the total growth period, the firstborn child matures before the youngest child is born, giving the middle child a period of exclusive attention.

Sibship size. How do resource handicaps change as a function of increasing family size? As Figure 3 shows, the middleborn resource handicap increases as a function of increasing family size (here, assuming a 18-year growth period). This happens because an increased number of children entails fewer resources for each individual child. Firstborns and laterborns are less strongly affected by this resource depletion because they still benefit from having some period of exclusive attention in which resources are not shared. Sibship size also affects the size of the laterborn and earlierborn resource handicaps; both effects become more extreme as the size of the family increases. Technically, the sibship size effect should eventually dissipate with increasing family size if families become so large that older siblings leave home before the younger ones are born, but in practice we expect this situation to be exceedingly rare.

\section{Tests of the Three Handicap Predictions}

Up to this point in our argument, all observations have been purely theoretical. Is there any evidence for these analytical expectations of a cumulative inequality effect? To answer this question, we now turn to the published literature. Parental investment studies have been carried out across several disparate disciplines. To identify studies that empirically measure parental investment, we conducted a literature search through four different databases: SocioFile (sociology), EconLit (economics), Biosis Preview (biology), and PsycINFO (psychology). In all four data bases, we searched for the key words birth order in combination with $p a-$ rental (we used parental rather than the technical term parental investment, for which various other terms such as parental behavior, or parental treatment are also used). ${ }^{4}$ To further extend the sample of studies appropriate to test the handicap predictions, we also combined birth order with three specific parental resource terms, namely, time (in EconLit), vaccination (in Biosis), and college expenses (in EconLit and SocioFile). All four searches yielded a combined total of 379 articles.

We read the title and abstract of each article to identify those that could possibly be relevant for testing the predictions of the equity heuristic. If there was any indication that the amount of parental investment (in terms of time, money, vaccination records, nutrition, etc.) was empirically studied as a function of birth order, we read the complete article. We then culled this group, keeping only those articles that (a) provided direct measures of parental investment, (b) distinguished between birth ranks (rather than between firstborn and laterborns), and (c) reported birth ranks in combination with family size (if cumulative investment was mea-

\footnotetext{
${ }^{4}$ The four databases covered the following time range: EconLit (1969December 1999), SocioFile (1974-1999), Biosis Preview (1985-1999), and PsycINFO (1887-1999). For the EconLit search we also used the key word birth order only because the combination of birth order and parental only yielded three hits; using birth order only yielded 23 more hits. In all four databases, we limited the search to English language journal articles.
} 


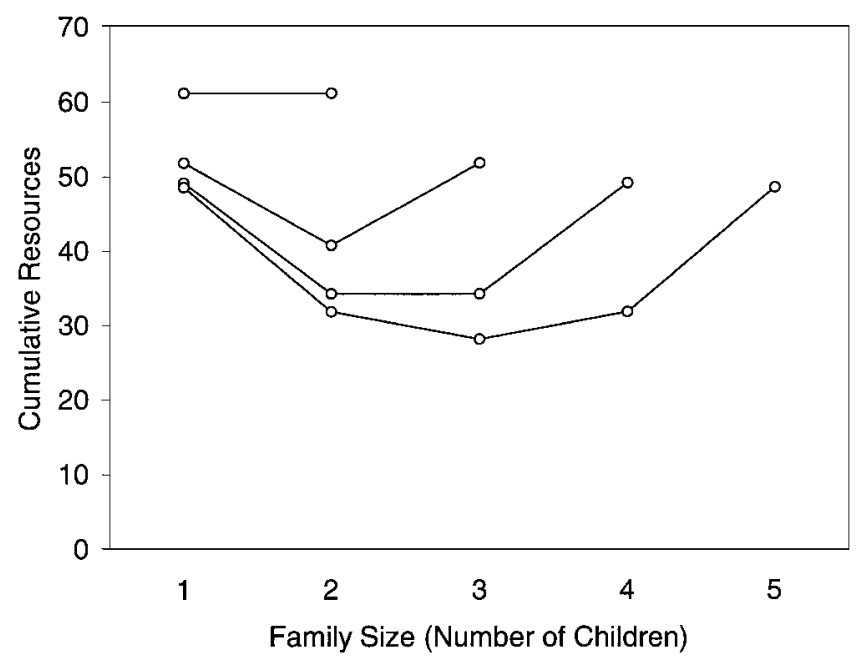

Figure 3. Cumulative resources as a function of family size (assuming a 18-year growth period). Cumulative investment equals the total amount of investments expressed as a percentage of the total resources the only child receives. The number of children is represented by the number of dots on a line.

sured). ${ }^{5}$ If one of the articles referenced a study that appeared relevant, we also looked it up and included it if the study met the described criteria. We found a total of nine studies: all the studies listed in Table 1 as well as Lindert (1977), Taubman and Behrman (1986), and Steelman and Powell (1989).

Two features of the parental investment literature may account for why this sample is relatively small. The first is that, as Borgerhoff Mulder (1998) pointed out, "most studies of parental investment in humans ... rely on outcomes (such as survival probabilities, educational attainment, or marital placements) as proxies for parental investment" (p. 136). In contrast, to test the equity heuristic we focus on direct measures of parental investment. The second feature is that different studies tend to include different moderating variables, and by no means do all studies include the variables that are necessary to test the handicap predictions (e.g., birth order and family size). In the following sections, we test the handicap predictions against the evidence reported in the set of nine studies.

\section{Is There Evidence for a Middleborn Resource Handicap?}

We found only one study (Lindert, 1977) that analyzed cumulative resource allocation as a function of birth rank and family size. $^{6}$ This study used time-use surveys of 1,296 Syracuse families in 1967-1968 to infer how much child-care time each child in the family received (each child had completed schooling). Lindert used regression analysis to derive the relationship between time spent in child care by all people in the household and the ages and number of children living in the household. He then used this regression model to estimate the total care time received by each child (corrected for the number and ages of the siblings) over the 18 years that he or she spent in the household (for details, see Lindert, 1977, p. 213). Figure 4 shows the distribution of childcare time as a function of birth order, family size, and (average) child spacing; child-care time is expressed relative to the childcare time for an only child.

Time is a limited resource that parents divide among offspring. Thus, according to the equity heuristic, its cumulative distribution should reveal a middleborn handicap in families of three or more, and it does in each case. Also consistent with this heuristic is the lack of a birth order effect in two-child families. In five out of the nine test cases (all families with more than two children), the resources received for the first and last birth rank are (almost) identical, and in four cases the lastborn child receives slightly more than the firstborn child. However, this advantage is relatively minor compared with the middleborn resource handicap. As predicted by the equity heuristic, the size of the middleborn resource handicap increases with increasing sibship size (see, e.g., the three-child, four-child, and five-child families in the 4-year childspacing chart in Figure 4), and the middleborn resource handicap also increases as a function of interbirth interval (although we urge caution in evaluating the latter result because Lindert, 1977, reported the average interbirth intervals). ${ }^{7}$ One finding is inconsistent with the middleborn handicap prediction of the equity heuristic: In each of the four-child families in Figure 4, the secondborn child received less of the cumulative resources than the thirdborn child, but this birth rank is still at a disadvantage compared with the first and fourth birth rank, which is consistent with the overall prediction.

\footnotetext{
${ }^{5}$ For analyses of the distribution of cumulative resources, family size is an important moderating variable. To see this, consider the birth rank secondborn as an example. Dependent on the size of the family, secondborns can functionally be lastborns (in two-child families), middleborns (in three-child and four-child families), or earlierborns (in families of five or more children). If one averages the cumulative resources for secondborns - regardless of family size and their actual functional role- then the resource distribution can become distorted. Take the resource allocation depicted in Figure 1. If one collapses the resources for each birth rank across family sizes (only child, two-child, and three-child families), the U-shaped (or quadratic) effect in the three-child family would disappear: Expressed as a percentage of the total resources the only child receives, the firstborns then receive $72 \%$ of the resources, the secondborns $65 \%$, and the thirdborns 58\%. Thus, the cumulative resource allocation seemingly follows a linear rather than a quadratic trend. This problem does not arise for those resources that are most critical at the beginning of a child's life. Here only the presence of older children is crucial (because younger children join the family when those resources are no longer critical or are less critical). Thus, we can also use studies that report birth ranks only to test for the laterborn resource handicap.

${ }^{6}$ We found several studies that analyzed allocation of parental time to children (e.g., C. R. Hill \& Stafford, 1974, 1980; Leibowitz, 1974a, 1974b, 1977). Unfortunately, those studies did not provide information about either birth order or family size — both of the variables necessary to test the middleborn resource handicap. Other studies reported birth order and family size information but did not observe actual parental time allocation. Instead they used, for instance, children's achievement patterns as a function of the cumulative parental input (e.g., Hanushek, 1992).

${ }^{7}$ Lindert's index of child-care time also includes the time older siblings spent taking care of younger kids. This fact may account for some patterns in the data that are also not predicted by the equity heuristic. For instance, with longer interbirth interval ( 3 and 4 years) the firstborn may take care of laterborns, thus explaining why the youngest child appears to receive slightly more resources than the firstborn child.
} 


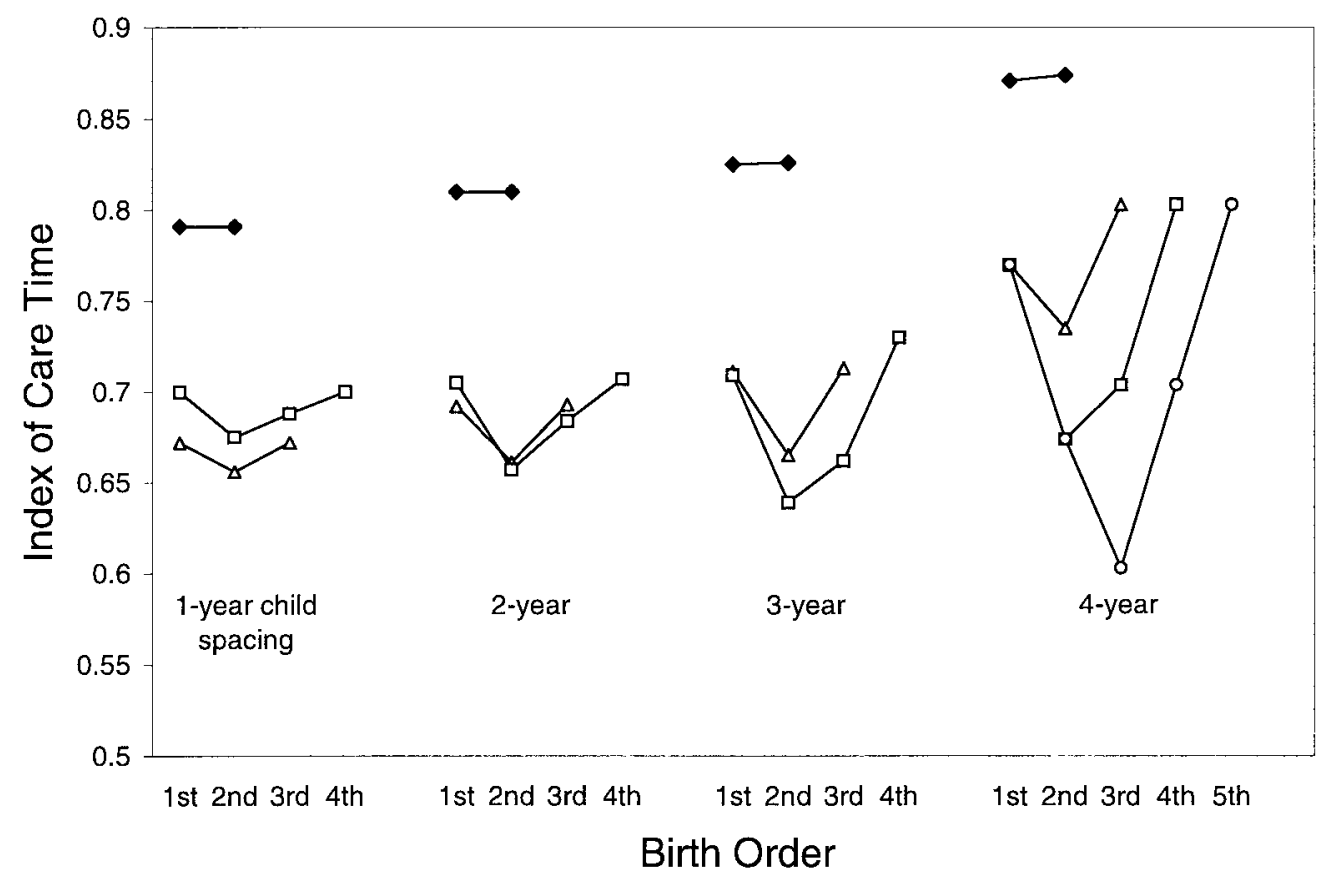

Figure 4. Distribution of total child care as a function of birth rank, family size (two, three, four, or five children; the number of children is represented by the number of symbols), and average interbirth interval. Data are from Table 4 of "Sibling position and achievement," by P. H. Lindert, 1977, The Journal of Human Resources, 12, p. 212. Copyright 1977 by The University of Wisconsin Press. Adapted with permission. The figure represents child-care time as a fraction of that predicted for an only child $(1.0=8,227 \mathrm{hr})$. Interbirth interval was coded such that, for instance, 2-year average spacing covered periods including 1.5 to 2.5 years (see Lindert, 1977, p. 207).

Since the early 1980s, an increasing number of studies have observed that middleborns appear to be different from firstborns and lastborns on various dimensions of well-being (e.g., Griffore \& Bianchi, 1984; Richter, Richter, Eisemann, \& Mau, 1997). Unfortunately, these studies do not include direct measures of parental investment, and thus do not enable us to strictly test the predictions of the equity heuristic. Nevertheless, this emerging picture of middleborn effects on well-being is certainly not inconsistent with the middleborn resource handicap predicted by the heuristic. We briefly describe one piece of this picture: Salmon's work on family sentiments. In a series of studies, Salmon (1998, 1999; Salmon \& Daly, 1998) uncovered large and consistent middleborn effects when she asked college students (19- to 22year-olds) about kinship and family ties. For instance, when asked to whom they would turn for emotional or financial support, first and lastborns were significantly more likely than middleborns to nominate a parent in both scenarios (by an overall factor of 1.5). First and lastborns were also significantly more likely to nominate their mothers as the person to whom they felt the closest, a pattern that was replicated in three separate studies (Salmon \& Daly, 1998, see also Kennedy, 1989; Rohde et al., 2002). Middleborns' family sentiments are also associated with less frequent contact with parents and grandparents.

If one assumed that cumulative parental investment shapes children's sentiments toward their family, then the equity heuristic could account for some of the above findings. For instance, the equity heuristic suggests that middleborns' more negative family sentiments and less close ties to their families may be related to lower cumulative parental investment and that firstborns' and lastborns' closer relationship to their families may stem from higher cumulative parental investment. However, we urge caution in drawing such conclusions. Ideally, to predict how (in)equality in parental investment affects various dimensions of children's wellbeing, one needs an understanding of the mechanism through which the type of invested resource influences the dimension of well-being being analyzed. We do not know of any studies that present such causal analyses.

\section{Is There Evidence for a Laterborn Resource Handicap?}

B. A. Kaplan, Mascie-Taylor, and Boldsen (1992) analyzed the relationship between birth order and health status in a British national sample. This study used the National Child Development Study, a British national survey sampling more than 18,500 children born in Great Britain during the first week of March 1958, to examine the relationship between birth order and a variety of health-related and medical experiences in young children. The survey measured such variables as immunization records and attendance at infant and toddler welfare clinics. These are measures of parental investment primarily from early childhood, during the time period when, according to the equity heuristic, each additional child in the family is expected to suffer a decrease in the total amount of parental investment received. We therefore expect to see a laterborn resource handicap in these data. This linear effect 
Table 1

Studies That Provide a Test of the Laterborn Resource Handicap

\begin{tabular}{|c|c|c|c|}
\hline Authors & Research question & Sample & General results \\
\hline Horton (1988) & $\begin{array}{l}\text { What is the effect of birth order } \\
\text { on child nutritional status, as } \\
\text { measured by children's } \\
\text { height and weight for their } \\
\text { age? }\end{array}$ & $\begin{array}{l}1,903 \text { households in the Bicol } \\
\text { region of the Philippines } \\
\text { (children age } 15 \text { or } \\
\text { younger) }\end{array}$ & $\begin{array}{l}\text { In the within-family sample (but much less so in the } \\
\text { pooled data-for possible reasons see Horton, } \\
\text { 1988, p. 350), the higher the birth order, the more } \\
\text { nutritionally disadvantaged children are }(r=17) \text {. } \\
\text { For example, "the last-born child in a family of } \\
\text { seven has a height for age (long-run nutritional } \\
\text { status) which is .5 SD-2.5 SD below that of the } \\
\text { firstborn" (p. 350). }\end{array}$ \\
\hline Barreto \& Rodrigues (1992) & $\begin{array}{l}\text { Which factors affect vaccination } \\
\text { adherence for measles, polio, } \\
\text { and other diseases? }\end{array}$ & $\begin{array}{l}455 \text { children in an urban area } \\
\text { in Sao Paulo, Brazil (all } \\
\text { children born from } 1971 \text { to } \\
1981 \text { who were registered } \\
\text { at a public health system) }\end{array}$ & $\begin{array}{l}\text { Next to year of birth, "birth order was also strongly } \\
\text { associated with vaccination completeness" (p. } \\
\text { 360). Calculated in terms of odds ratios, } \\
\text { laterborns were less likely to receive vaccination } \\
\text { than firstborns. Specifically, secondborns, third- } \\
\text { and fourthborns, and fifthborns (and still laterborn } \\
\text { children) were only } 0.71,0.63 \text {, and } 0.42 \text { as likely } \\
\text { as firstborns to receive vaccination, respectively. }\end{array}$ \\
\hline B. A. Kaplan et al. (1992) & $\begin{array}{l}\text { What is the relationship } \\
\text { between birth order and a } \\
\text { variety of health-related and } \\
\text { medical experiences (e.g., } \\
\text { immunization records, } \\
\text { attendance at infant and } \\
\text { toddler welfare clinics) in } \\
\text { young children? }\end{array}$ & $\begin{array}{l}\text { National Child Development } \\
\text { Study, a British national } \\
\text { survey sampling more } \\
\text { than } 18,500 \text { children born } \\
\text { in Great Britain during the } \\
\text { first week of March, } 1958\end{array}$ & $\begin{array}{l}\text { Fewer laterborns attended toddler clinics and } \\
\text { laterborns were less likely to be immunized (for } \\
\text { diphtheria, small pox, polio) than firstborns } \\
\text { (based on } 1965 \text { immunization records). The } \\
\text { percentage of firstborn, secondborn, thirdborn, } \\
\text { and fourthborn (and higher birth orders) children } \\
\text { who attended toddler clinics was } 63,56,49 \text {, } \\
\text { and } 44 \text {, respectively. The percentage of children } \\
\text { who were immunized against childhood diseases } \\
\text { (diphtheria, small pox, polio) was } 93,90,86 \text {, } \\
\text { and } 79, \text { respectively. }\end{array}$ \\
\hline Li \& Taylor (1993) & $\begin{array}{l}\text { Which factors affect vaccination } \\
\text { adherence (measles, mumps, } \\
\text { and rubella)? }\end{array}$ & $\begin{array}{l}\text { 7,841 children born in } \\
\text { January to March } 1990 \text { in } \\
\text { the northeast and northwest } \\
\text { Thames regions (aged } 19 \\
\text { to } 21 \text { months at the time of } \\
\text { data collection) }\end{array}$ & $\begin{array}{l}\text { Among other indicators of parental attention, } \\
\text { percentage of children receiving vaccination is } \\
\text { affected by birth order: Firstborns (43), } \\
\text { secondborns (32), thirdborns (15), fourthborns (6), } \\
\text { fifth- and laterborns (4). Li \& Taylor concluded } \\
\text { that each "unit" of increase in birth order was } \\
\text { responsible for a decrease in the odds of being } \\
\text { vaccinated by about } 20 \% \text {. They speculated that } \\
\text { parents with other children to take care of "may } \\
\text { find it difficult to get around to having their } \\
\text { children immunized" (p. } 170) \text {. }\end{array}$ \\
\hline Lewis \& Britton (1998) & $\begin{array}{l}\text { What is the relationship } \\
\text { between birth order and } \\
\text { measles vaccination? }\end{array}$ & $\begin{array}{l}\text { 6,350 children born in one } \\
\text { week of April } 1970 \text { in } \\
\text { England, Scotland, and } \\
\text { Wales (immunization was } \\
\text { recorded at age 5) }\end{array}$ & $\begin{array}{l}\text { The percentage of children receiving vaccination } \\
\text { was } 68,58,50,39 \text {, and } 34 \text { for firstborns, } \\
\text { secondborns, thirdborns, fourthborns, fifthborns } \\
\text { (and higher birth orders), respectively. }\end{array}$ \\
\hline Angelillo et al. (1999) & $\begin{array}{l}\text { Which factors affect mandatory } \\
\text { vaccination adherence } \\
\text { (poliomyelitis, tetanus, } \\
\text { diphtheria, hepatitis B)? }\end{array}$ & $\begin{array}{l}841 \text { infants who attended } \\
\text { public kindergarten in } \\
\text { Cassino and Crotone, Italy }\end{array}$ & $\begin{array}{l}\text { Among various mother and child attributes, only } \\
\text { birth order "significantly predicted vaccination } \\
\text { nonadherence" (p. 226). Calculated in terms of } \\
\text { odds ratios, laterborns were only } 0.73 \text { as likely as } \\
\text { firstborns to receive vaccination ( } 95 \% \text { confidence } \\
\text { interval: } 0.57-0.95) \text {. }\end{array}$ \\
\hline
\end{tabular}

a In their Table III, Barreto and Rodrigues (1992) reported the odds ratio for lack of vaccination (compared with a firstborn). Here we reversed their odds
ratios. ${ }^{\mathrm{b}}$ The results are calculated from the frequency data reported in Kaplan et al.'s (1992) Tables 1 and 2 (we pooled across socioeconomic status).

is exactly what B. A. Kaplan et al. found. Table 1 shows the percentage of children who attended toddlers' clinics and who were immunized against childhood diseases (diphtheria, small pox, and polio) as a function of birth order. Fewer laterborns attended toddler clinics, and laterborns were less likely to be immunized than firstborns. We agree with B. A. Kaplan et al. (1992), and similarly with Li and Taylor (1993), that this effect may be the result of competition for parental time: Parents with older children have less time available to take their younger children to the clinic.

In addition to the B.A. Kaplan et al. (1992) study, we found five other studies that can be used to evaluate the laterborn handicap prediction. Table 1 summarizes the results obtained in those studies. Most studies in Table 1 analyzed vaccination adherence during early childhood (e.g., measles, polio, mumps, and rubella) as a function of birth order. Consistent with B. A. Kaplan et al.'s (1992) findings, four large-scale surveys (see Angelillo et al., 1999; Barreto \& Rodriguez, 1992; Li \& Taylor, 1993; Lewis \& Britton, 1998) consistently observed that the percentage of children who received vaccination declines as a function of birth order; that is, younger children are less likely to receive complete vaccinations or to be vaccinated at all.

We also found one study that examined the effect of birth order 
on child nutritional status as measured by children's height for their age. Horton (1988) used a within-family sample in addition to a pooled sample. One of the dependent variables used was the deviation of the individual child's long-run nutritional status from the household mean (expressed in terms of $z$ scores above or below the U.S. reference population). In the within-family sample, Horton found the effect of birth order to be significant, with children from higher birth ranks being more poorly nourished (see Table 1). ${ }^{8}$ One observation relevant for our discussion of the equity heuristic is that Horton did not observe an effect of birth order on current nutritional status (as measured by children's weight for height). In her view, this finding

suggests that parents at a single point in time seem to allocate resources relatively equitably among children of different birth orders. However, the long-run outcome is far from equitable, since later-born children are born when per capita resources are smaller. (p. 349)

Increased malnourishment and lack of vaccination may also contribute to why laterborn children tend to be shorter than earlierborn children (see Davie, Butler, \& Goldstein, 1972; Goldstein, 1971) and why they suffer higher mortality rates in developing countries (e.g., Brittain, 1992; Hrdy, 1999; Scheper-Hughes, 1992; Scrimshaw, 1978, 1984; for conflicting evidence, see Lynch \& Greenhouse, 1994, who found that the probability of dying as an infant in 19th-century Sweden, according to birth order, is U-shaped). For instance, in her analysis of 4,275 births that took place on the island of St. Barthélemy (French West Indies) between 1878 and 1970, Brittain (1992) found that children (ages $>2$ weeks but $<1$ year) of maternal and paternal higher birth order are more likely to die than children of lower birth order ( eta $=.05$ and .06 , respectively). Brittain suggested that the higher mortality rates in early childhood were not due to endogenous or gestational factors but probably due to "exogenous or social factors such as the availability of maternal time or family resources" (p. 1266).

In addition, Ballweg and Pagtolun-An (1992) reported that in their sample of 986 women from the Northern Mindanao region of the Philippines "the higher is the birth order of a child, the greater is the chance that the child will die before reaching age five" (p. 85; birth order, independent of other factors, explained more than $30 \%$ of the variation in infant and child mortality). According to their regression and structural equation analyses, less parental investment (e.g., as measured by the frequency of parental care and the quality and quantity of nutrition) "represents a significant link in the association between birth order and infant and child mortality" (p. 85). Finally, in a study of 14,192 children born in Sweden between 1915 and 1929, Modin (2002) observed that laterborn children generally have higher mortality than firstborn children. For instance, the odds ratio of dying before age 10 among third- and fourthborns relative to firstborns was 2.65 for girls and 1.54 for boys (Table 5 in Modin, 2002). In middle and old age, however, mortality varied little with birth rank, suggesting that the long-term influence of birth rank on mortality is "partly mediated by adult social class, education and income" (Modin, 2002, p. 1051).

Some of the studies included in Table 1 afford us the opportunity to examine whether the size of the laterborn resource handicap depends on the families' socioeconomic status (SES). On average, the results suggest that it does not. In the context of children's nutritional status, Horton (1988) observed that "higher asset own- ership is apparently not particularly important in reducing inequality among siblings" (p. 351), and Barreto and Rodrigues (1992) reported that "family income per capita did not influence vaccination uptake" (p. 359; for a similar conclusion, see Lewis \& Britton, 1998). Only B. A. Kaplan et al.'s (1992) data suggest that the laterborn resource handicap tends to be more pronounced for families of lower SES (represented by fathers in less skilled occupations): Specifically, the percentage of firstborns who were immunized against childhood diseases (diphtheria, small pox, polio) was four percentage points lower for families of lower SES compared with firstborns from families of higher SES, whereas for thirdborns and fourthborns (and higher birth orders), this difference amounted to eight and seven percentage points (calculated from B. A. Kaplan et al.'s, 1992, Table 2). In the General Discussion section, we return to the question of why the laterborn resource handicap, on average, appears to be largely independent of a family's SES.

\section{Is There Evidence for an Earlierborn Resource Handicap?}

The earlierborn resource handicap suggests that there may be resources, such as an allowance, or privileges that are exclusive to the last years of a child's development. For these resources, the earlierborn children are at disadvantage compared with the laterborn children. One of these resources is the ability of parents to cover the expenses of a postsecondary education for their children. The American system of higher education assumes contributions from the family toward meeting college expenses. Although we found numerous studies that were concerned with the relationship between economic support and higher educational outcomes, many could not be used here because they either did not empirically test the relationship or they did not include birth order and sibship size information (see the references in Steelman \& Powell, 1989). ${ }^{9}$

We found two studies that pertain to the earlierborn resource handicap. Taubman and Behrman (1986) analyzed 1-year college room and board expenses and found that "the larger one's family, the more heavily one relies on scholarships and loans and the less heavily on parental contributions" (p. 33). In contrast to the prediction derived from the equity heuristic, they did not find birth order effects in the sources of funding for college (e.g., monetary resources available from parents or from working) — a finding they speculated could be due to the small sample size.

\footnotetext{
${ }^{8}$ Horton (1988) did not report the children's average age as a function of birth order. However, because she restricted her analysis to children age 15 years or less, and the average number of children per family was 6.8 , one can infer that the laterborn children were relatively young. This is important. If degrees of malnutrition coincide with critical developments such as the rapid brain growth in early years of life, it is likely to have cumulative consequences (by age 2, the brain already weighs $75 \%$ of its eventual adult weight and by age 5, it has grown to $90 \%$; Berger, 2000; see also Huttenlocher, 1994).

${ }^{9}$ In addition to the key words college expenses and birth order, we also used the key word education. Although we found numerous studies that explored the relationship between birth order and schooling or educational attainment (e.g., Behrman \& Taubman, 1986; Kuo \& Hauser, 1996; Steelman, 1985; Travis \& Kohli, 1995), we did not uncover any additional studies that explored how many financial resources parents invest in their children's education as a function of their birth order.
} 
In their study of 3,279 college students who entered college in the fall of 1972 (data stemmed from the National Longitudinal Survey of high school seniors from both public and private schools in the United States), Steelman and Powell (1989) also investigated the influence of number of siblings and birth order on financial arrangements for college. Using regression models, the authors estimated both the likelihood of parental assistance and the extent of parental contribution. For this sample, they found that "sibship size has a very strong negative influence on the amount of parental aid, whether the amount is measured in absolute dollars or as a proportion of total college costs" (p. 850). This result is consistent with the equity heuristic, which predicts a reduction of resources per child (at any given time) with increasing sibship size. The authors also reported that the number of younger siblings is associated with a larger reduction in parental support than the number of older siblings, "suggesting an advantage to laterborn children" (pp. 849-850). Specifically, the "effect of the number of younger siblings is over twice that of the number of older siblings" (p. 850). This finding also conforms to the equity heuristic if one assumes that, by the time a child requires resources that are exclusive to the last years of a child's development, the older-but not the younger-siblings are less likely to still rely on parental resources.

\section{General Discussion}

Although we urge caution in evaluating the results from the relatively small sample of studies that we were able to identify from our review of the existing literature, it seems fair to conclude that the equity heuristic provides a parsimonious explanation for the diverse findings obtained. This heuristic explains why Lindert (1977) found a middleborn resource handicap in the cumulative distribution of invested time in the three-child, four-child, and five-child families. It suggests that fewer cumulative resources may be one reason why middleborns appear to be different from firstborns and lastborns on diverse measures of well-being. Furthermore, the equity heuristic also explains why for medical and nutritional resources that are most important in the early years, multiple large-scale studies have consistently found a laterborn handicap. Finally, the equity heuristic provides an explanation for why Steelman and Powell (1989) reported that earlierborns have a disadvantage in expenses for postsecondary education.

In the following discussion, we distinguish between different classes of parental resources. We then review various alternative explanations for birth order effects and put forth the idea of parental resource allocation as an example of adaptive decision making. We conclude with a discussion of the developmental implications of the equity heuristic.

\section{Parental Investments: Some Steps Toward a Taxonomy}

In his classic work, Trivers (1972) defined parental investment as any cost associated with raising offspring that reduces the parent's ability to produce or invest in other offspring. In recent years, there has been an increasing recognition among behavioral ecologists of the multidimensional nature of parental investments (see Borgerhoff Mulder, 1998, p. 147). In accordance with this recognition, we propose that at least three general classes of parental resources can be distinguished: (1) material resources such as food, health care, and money for higher education; (2) cognitive resources such as intellectual stimulation as well as other forms of time spent training and instructing children; and (3) interpersonal resources such as attention, time, love, affection, and general encouragement by parents.

In theory, it appears important to distinguish between these resource dimensions because the transmission mechanisms between the type of invested resource and outcome (in terms of the child's health, education, or psychological well-being) are not likely to be the same across the resources. Pragmatically, it is worth distinguishing between these resources because each class is tied to a different research literature, set of models, and associated tests and controversies. Cognitive resources, for instance, are most closely associated with the debate over whether birth order differences in IQ really exist (as proponents of the confluence theory argue) or whether family-size effects alone exist (as proponents of dilution theories insist). We return to this debate below. Clearly, the above dimensions are not exhaustive, and a comprehensive classification of parental resources may also include distinctions based on the following properties.

Resource limits. Some resources are naturally limited and thus will, all else being equal, not significantly vary as a function of a family's SES. Let us take interpersonal resources such as attention as an example. A parent has only a limited amount of attention available and thus needs to divide it among offspring. Material resources, in contrast, hinge on a family's SES. Thus, all else being constant, one may speculate that material resources vary more across families (as a function of their SES), whereas the pool of interpersonal resources may tend to be more constant across families.

"Gatekeeper" resources. When testing the handicap predictions of the equity heuristic against the available evidence, we consistently observed that the percentage of children who receive vaccination declines as a function of birth order. B. A. Kaplan et al. (1992) suggested that this tendency is the result of competition for parental time, whereby parents with older children have less time available to take their younger children to a clinic (see also Horton, 1988, p. 351, for discussion of the constraining role of parental time in the context of children's nutritional status). If so, this finding suggests that certain parental investments such as vaccination are withheld, not because financial resources available for health care are depleted-in fact, vaccination is typically provided for by health care systems-but because another resource, parental time, is available to a lesser degree. That is, some key resources serve as a gatekeeper for other resources, enabling or disabling other investments, thus providing one candidate explanation for why the laterborn resource handicap for health care seems to be independent of a family's SES.

Surrogate resources. Parents are not the only ones to invest in children. Older siblings, grandparents, and sometimes even unrelated individuals can also provide resources. More generally, in kin-based societies such as the pastoralist peoples of Africa, families are embedded in a wider kin network in which reciprocal investment in the children of kin is common (Ivey, 2000). The availability of such surrogate resources has implications for the equity heuristic's predictions. In its present formulation, the predictions of this heuristic are relevant only in domains in which the majority of investment comes from parents, and for this reason, we must caution that an analysis based on the equity heuristic should 
apply only to situations in which a child's kin (e.g., grandparents) do not provide substantial surrogate resources that compensate for parental ones. We should also note, however, that surrogate resources may well be invested in offspring according to the equity heuristic, in which case their effect would be fully consistent with the expectations derived from this heuristic. For instance, grandparents who often have more grandchildren than children may choose to divide their resources equally, thus benefiting from a distribution principle which is easily defensible (to parents and grandchildren) in that it does not differentiate between the recipients.

\section{Alternative Explanations for Birth Order Effects}

In what follows, we briefly describe four other accounts proposed to explain birth order effects, namely, the resource dilution hypothesis, the confluence model, the admixture hypothesis, and the family dynamics model. Each of these models-which are not mutually exclusive- - has received considerable, if still hotly debated, empirical support.

The resource dilution hypothesis. One domain that consistently shows effects of birth order, family size, and birth spacing is academic achievement. This form of achievement is typically measured through standardized test scores or number of years of education. The standard finding is that laterborn children, children in larger families, and children with siblings who are close to them in age perform worse on these measures (Heer, 1985, 1986; Powell \& Steelman, 1993; Taubman \& Behrman, 1986). Some of these effects persist even when academic ability is held constant (Powell \& Steelman, 1993). Birth order is also negatively correlated with children's educational aspirations and continues to affect occupational status into young adulthood (Marjoribanks, 1988, 1989).

Perhaps the most popular explanation that has been advanced for these findings is the resource dilution hypothesis (Blake, 1981, 1989; Downey, 1995, 2001; Lindert, 1977; Powell \& Steelman, 1989). Like the equity heuristic, this hypothesis takes as its basic assumption the fact that parental resources are limited. This hypothesis also postulates that children provided with greater intellectual, social, and economic resources will excel in academic and intellectual arenas. Therefore, as family size increases or birth spacing decreases, children are predicted to suffer from the depletion of resources. Reduced investment is in turn expected to translate into reduced achievement (Heer, 1985; Powell \& Steelman, 1993; but see Marjoribanks, 1991). Because their elder siblings reach each new academic stage before them, laterborn children may suffer from reduced investment as financial resources available for further education are used up. This effect appears to be stronger in middle-class families than in families with either abundant or scarce resources, and it may be compensated for in lastborn children if they are reared at more prosperous economic periods of their parents' life cycle (Travis \& Kohli, 1995).

The equity heuristic is itself a variant of the resource dilution hypothesis. In the form of its three resource handicaps, the equity heuristic postulates three alternative developmental outcomes that are dependent on the availability and importance of key parental resources at different periods in the life course. Like the equity heuristic, all resource dilution models assume the equitable distribution of parental resources, and some of these other models also consider the developmental consequences of life course timing in specific parental investments, such as education (Downey, 2001). Only the equity heuristic, however, formally highlights the unexpected consequences of parental investment in creating cumulative inequality from equality, and only the equity heuristic systematically applies this principle to an explication of diverse patterns of birth order effects.

The confluence model. First proposed by Zajonc and Markus (1975; see also Zajonc, Markus, \& Markus, 1979), this model attempts to specify how parental resources-conceived in terms of the intellectual environment that parents provide-translate into children's intellectual attainment. Like other resource dilution models, the confluence model posits that parental resources are finite and become depleted by the addition of offspring to the family. Unlike other resource dilution models, the confluence model includes a role for offspring themselves. Also unlike other resource dilution models, which have been applied to varied consequences of parental investment, the confluence model addresses itself only to intellectual ability.

One of the major insights deriving from the confluence model is that children can be treated as part of their own dynamically changing environments. Thus, the intellectual environment is defined as a function of the absolute intellectual levels of all family members, including the intellectual level of the person whose development is being analyzed. The confluence model assumes that the greater the intellectual maturity of people who interact with the growing child, the more mature the child's verbal, analytical, and conceptual experiences will be. Because children must share their parents' intellectual resources, each successive sibling is born into a more depleted intellectual environment. In larger sibships, however, elder siblings tend to enrich the family's intellectual environment as they approach adulthood, so lastborns may experience a more favorable environment in such families compared with middleborns. Various predictions based on the confluence model are supported by evidence from more than 50 different studies of birth order and intelligence (Zajonc, 2001).

Although application of the confluence model has previously been limited to trends in intellectual ability, this model could also be applied to behavioral domains, such as attachment behavior and psychological well-being, in which offspring are capable of providing surrogate resources. In general, such models would predict that initially linear trends by birth order become transformed into quadratic trends as laterborns (and particularly lastborns) benefit from an increased presence of surrogate resources within the family system.

The admixture hypothesis. Some critics of birth order research maintain that reported effects are mostly or entirely artifactual (Ernst \& Angst, 1983; Page \& Grandon, 1979; Rodgers, 2001). According to these theorists, birth order effects are generally spurious consequences of the failure of researchers to control for important background influences, especially sibship size and social class. Lower class families, for example, tend to be larger than upper class families and are therefore biased for an overrepresentation of laterborns. In uncontrolled studies, artifactual birth order effects can arise owing to between-family differences in sibship size, which are often mediated by associated differences in social class and other background variables. Some advocates of the admixture hypothesis insist that the only trustworthy studies are those that examine siblings who have grown up in the same family. 
Unfortunately, there are relatively few such within-family studies, and sample sizes in these studies tend to be small, giving them relatively modest statistical power compared with well-controlled, between-family studies.

To date, within-family studies of intelligence have generally yielded null results, in accordance with the predictions of admixture theorists (Rodgers, Cleveland, van den Oord, \& Rowe, 2000; but see Zajonc, 2001). By contrast, within-family studies of personality have consistently produced significant birth order differences (Chao, 2001; Paulhus, Trapnell, \& Chen, 1999; Price, 1969; Sulloway, 1999, 2001a). It is nevertheless possible that personality assessments by siblings and other family members are affected by stereotypes or by sibling contrast effects (a process whereby siblings magnify small differences in personality into larger ones). It is just as plausible, however, that birth order stereotypes reflect real differences in within-family roles and behavior, which siblings perceive and report as differences in personality.

Sulloway's family dynamics model. Sulloway (1996, 2001a) has discussed four different causes of birth order effects in personality and behavior as part of a family dynamics model of human development. The first causal mechanism is associated with differing levels of parental investment and is therefore a variant of other resource dilution models. When reproductive success is linked to scarce resources, such as land in agrarian societies, parents may invest more heavily in one offspring than another (typically firstborns and, to a lesser extent, lastborns). Sulloway's second causal mechanism builds on the observation that siblings tend to occupy differing niches within the family system. For example, firstborns often cultivate the niche of a surrogate parent. The third causal component of Sulloway's family dynamics model invokes the supposition that firstborns are bigger, stronger, and smarter than their younger siblings, and that they are therefore better able to use competitive strategies that take advantage of these traits. A fourth causal mechanism involves sibling deidentification, or the fact that adjacent siblings, in an effort to minimize direct competition, seek to differentiate themselves by becoming different in their interests, social attitudes, and personalities (Davis, 1997; Schachter, Gilutz, Shore, \& Adler, 1978; Skinner, 1992).

Sulloway $(1996,2001 \mathrm{a})$ has linked the first three of these four causal mechanisms to specific attributes within the Five Factor Model of personality (Costa \& McCrae, 1992; McCrae \& Costa, 1987). In addition, he predicts that most birth order effects involving personality should exhibit both linear and quadratic (U-shaped) trends. Linear trends are implicit in birth order's status as a proxy for differences in age, size, and strength, as well as in the potential for surrogate parenting. Quadratic trends are implicit in the tendency for parents to invest more in firstborns and lastborns relative to middleborns. Sulloway's family dynamics model also allows for the possibility that parental favoritism and sibling strategies will elicit counterstrategies. Some of these sibling counterstrategies are anticipated to entail quadratic birth order trends. For example, middle children, who are expected to receive less parental investment than other offspring, are also expected to be less conscientious than their siblings, when controlled for the linear effects expected in this personality dimension. In a study involving more than 4,000 subjects, Sulloway (2001a) found that the expected linear and quadratic trends associated with birth order and personality do exist in within-family data. Moreover, for each dimension of the Five Factor Model of personality, these various birth order trends (mean $r=.11$ ) agree closely with the predictions of his family dynamics model. The same general pattern of birth order effects has been found in studies of nonfamily members, although effect sizes are typically smaller than those obtained in withinfamily studies.

Although Sulloway's (1996, 2001a) family dynamics model and the equity heuristic both predict that parental investment will create quadratic trends in birth order effects, the two theories differ regarding how these effects will emerge on a developmental basis. In particular, the advantage to lastborns that is posited to occur under the equity heuristic can only emerge after other siblings have left the home, whereas the advantage for earlierborns should be present from early childhood. In contrast, the family dynamics model predicts that both effects should be present throughout childhood. We do not know of any study that uses direct measures of parental investment to test such age-contingent effects; however, there are studies that use indirect measures. For instance, Kidwell (1982; see also 1981) analyzed the self-esteem of a sample of young American males (15 to 16 years old) as a function of their birth order. She found that "middleborns have a significantly lower self-esteem than both firstborns and lastborns" (p. 225). Assuming the typical age spacing between children, the lastborns in Kidwell's study - being only 15 to 16-should not have exhibited more self-esteem than middleborns because they had yet to be alone in the family or had not been alone for more than a year or two. If one posits a direct link between the total amount of parental investment and self-esteem, Kidwell's finding would contradict the prediction of the equity heuristic and support that of the family dynamics model. Future work can provide strict tests of age-contingent birth order effects.

Strengths and limitations of the equity heuristic. In our view, what the equity heuristic contributes to an understanding of birth order effects, beyond these existing models, is the realization that a simple parental decision rule can, in principle at least, induce both linear birth order effects (by means of the laterborn and earlierborn resource handicaps) and quadratic birth order effects (by means of the middleborn resource handicap). This heuristic is thus more parsimonious than the family dynamics model, which postulates several different causal mechanisms to predict both linear and quadratic components. The equity heuristic also suggests ways to make predictions from the other models more specific. For instance, both the laterborn resource handicap and the resource dilution hypothesis share the notion of resource depletion with increasing family size. The equity heuristic, however, suggests resource dilution to be of particular relevance for resources that are critical for the earlier stages in life. Generally, it treats parental investment as multifaceted, thus acknowledging that parental resources are not just a single kind of resource.

The equity heuristic also has significant limitations. For instance, unlike the other approaches we have reviewed, it is more cautious in predicting how parental resources translate into behavior, intellect, or personality. We also think that (in its present formulation) the predictions of the equity heuristic are relevant only in domains in which the majority of investment comes from parents, and for this reason, we must caution that an analysis based on the equity heuristic should apply only to situations in which a child's siblings, or a child itself, do not provide substantial surrogate resources that compensate for parental ones. 


\section{Parental Resource Allocation: An Instance of Adaptive Decision Making?}

As we pointed out in the beginning of this article, the aim of our analysis is not to argue that parents necessarily follow the equity heuristic. Our point is much more modest-namely, to draw attention to the counterintuitive consequences that eventuate if they do so. Nevertheless, we must ask the question: How plausible is the equity heuristic as a decision strategy for parental resource allocation? We answer this question by way of a small detour to the related (yet unfortunately insufficiently connected) research field of behavioral decision making. In their work on the "adaptive decision maker," Payne, Bettman, and Johnson (1993) emphasized that a decision maker typically has a multitude of strategies available and chooses among them depending on their costs and accuracy, given circumstances such as time pressure or accountability.

Inspired by this view, we propose that parental resource allocation may be an instance of adaptive decision making. That is, parents are likely to have multiple investment strategies available, and the strategy selection would depend on circumstances such as time pressure, parental goals (e.g., conflict avoidance), social norms (e.g., egalitarian values), and the nature and extent of the resource involved. Thus, one may suggest that conditions such as time pressure and goals such as conflict avoidance favor-but do not necessitate - the use of the equity heuristic. This suggestion is consistent with the claim that dividing equally requires less information processing and calculation effort than other distribution principles (e.g., Messick, 1993; Ohtsubo \& Kameda, 1998, p. 91) and also has the benefit of being easily defensible in that it does not differentiate between the recipients (Messick \& Schell, 1992). ${ }^{10}$

There is, however, at least one important argument why the equity heuristic may not always be a plausible model for parental resource allocations: It allocates resources regardless of the recipients' situational and age-specific needs. An ill or a very young child, for instance, draws more care from parents than a healthy or an older child. Moreover, it seems likely that the effective allocation of resources, which are dedicated to the children's future social competitiveness (Geary, 2000; H. Kaplan et al, 1998), are influenced by feedback provided by children, for instance, in terms of their educational achievements. Because children's ability to benefit from investment in "embodied capital" is likely to be more variable then their ability to benefit from, for instance, nutrition, such feedback may override the equity heuristic. But do investments in children's future social competitiveness rule out the equity heuristic? Not necessarily. Although it may turn out that the equity heuristic is an inappropriate model for resources that target children's later social competitiveness, it may still be an appropriate model for the early stages of their allocation (i.e., prior to feedback about how effectively children use the investment).

Do age-specific needs rule out the equity heuristic? There exists a body of research that suggests that parents may treat each successive child equally at the same age rather than treating children equally at any given point in time. Dunn, Plomin, and colleagues (Dunn \& Plomin, 1986; Dunn, Plomin, \& Daniels, 1986; Dunn, Plomin, \& Nettles, 1985) have concluded that mothers are quite consistent in their treatment of each successive child when children are at the same age, and change their maternal behavior as the child ages. If each child is, in fact, treated strictly equally at the same age, this form of implementation of the equity heuristic will not yield the kind of resource handicaps we identified. However, it is important to point out that dilution of parental resources (such as time and attention) makes truly equal treatment at the same ages unlikely if not impossible. This is likely to be true even when age-specific needs are most pronounced: A newborn of a mother having two children is not likely to receive the same amount of attention (or probably health care) as a newborn who is an only child. Hence, age-specific parental investments will almost always be diluted by increases in family size.

In addition, to respond appropriately to age-specific needs, parents might reasonably attempt to find a compromise between equity and age-specific needs. Under this circumstance, the equity heuristic would provide a weight, pulling the allocated resources toward an equal split, which is then modified by parents' attempts to meet each child's age-specific needs. Such a compromise can still produce resource handicaps. To illustrate, let us assume the same distribution of resources as depicted in Figure 1, but that in addition, the secondborn and thirdborn in their first period of growth receive an additional one-tenth of the total resources. Even then, the various resource handicaps still continue to exist. For example, the middleborn resource handicap (calculated as a proportion of the total investment in an only child, see Figure 1) changes as follows: for firstborns, from $54 \%$ to $51 \%$; for middleborns, from $42 \%$ to $43 \%$; and for lastborns, from $54 \%$ to $57 \%$. In addition, there are certain limited resources that would be difficult to equalize as a function of children's ages and as the number of children in a family increases. Of course, there may be other resources, such as the nature of the attention a child receives, that are equalizable. Thus, the equity heuristic and an age-specific decision rule can both be plausible and independent candidates for parents' adaptive investment strategies, and they may operate simultaneously depending on the resource, or they may serve as interdependent motives between which parents attempt to find a satisfactory compromise.

\section{Parental Investment and Children's Well-Being: Two Sides of the Same Coin?}

Although we have speculated about how a particular resource might impinge on children's development (e.g., malnourishment and size), our analysis has focused primarily on the resources (and their distributions) rather than on their consequences. Despite this limited focus, our analysis seems to imply that more parental investment is invariably good for children. Is it actually true that more investment is always better? We do not believe so. Whereas there may be linear relationships between resources and children's well-being (e.g., in the context of health care), assuming such linear relationships across all stages of children's development and across resources would be naive and would contradict findings and theories from developmental psychology.

By way of illustration, consider a classic study in the framework of life course theory. In Children of the Great Depression, Elder

\footnotetext{
${ }^{10}$ In the context of parenting, an equity motive may not always be easy to realize, nor may equity always be easy to assess. For example, does getting up three times in the middle of night to feed an infant for a total of 2 hr really equate chaperoning the infant's older sibling to a 2-hr movie?
} 
(1974) showed that parents and children often worked out successful adaptations to drastic reductions in family's resources resulting from the economic depression of the 1930s. As Elder (1998) has noted about potentially positive outcomes of resource exhaustion, "the developmental impact of a succession of life transitions or events is contingent on when they occur in a person's life" (p. 3). In the context of parental investment, this observation implies that the (possibly cumulative) consequences that a resource advantage or disadvantage has depends on when it occurs in a child's life. Take as an example the time of exclusive parental care. As Figure 1 illustrates, firstborns enjoy exclusive care at an early stage of their lives, whereas lastborns experience such exclusive care at a late stage in their development (during adolescence). Will this different timing yield differential effects? Some attachment theorists would strongly suggest so. Attachment is typically defined as a close emotional bond between the infant and caregiver, and it is assumed that this bond, among others, rests on the availability of parental care and attention. For example, securely attached babies have caregivers who are consistently available to respond to their infants' needs (Santrock, 2002, p. 189). In particular, the early attachment theorists such as Erikson (1968) and Bowlby (1988) emphasized the first year of life as the key period for the development of attachment (see Kagan, 1987, for a different view). If this were true, and if early attachment to a caregiver were crucial and foreshadowed later functioning (Schneider, Atkinson, \& Tardif, 2001), then firstborns would profit much more from the period of exclusive care than lastborns. Such a prediction could be tested both in terms of children's attachments (and adolescents' family sentiments, Salmon, 1998) and their cognitive and emotional functioning. What these considerations also suggest is that one has to be cautious in drawing conclusions from, for instance, the distribution of child-care time reported in Figure 4. Although the first and last birth ranks receive (almost) identical child-care time, lastborns might not profit from the availability of resources to the same degree as the firstborns because the period of exclusive care may come too late to have a significant impact on the person's development.

In addition to the insight that parental investment and children's well-being are often not linearly related, developmentalists have also, more fundamentally, highlighted the importance of parental treatment for children's development. They stress, for instance, how different two children growing up in the same household can become. Although there is not yet a comprehensive causal model explaining such differences (Mekos, Hetherington, \& Reiss, 1996), work in behavior genetics suggests that within-family variations are not due to genotypic differences alone but also to differences in family environment (e.g., Plomin \& Daniels, 1987). In other words, children reared in the same family can receive different parental treatment (e.g., Brody, Stoneman, \& Burke, 1987; Daniels \& Plomin, 1985). ${ }^{11}$ Differential parental treatment in turn has been consistently demonstrated to be associated with adolescent adjustment (e.g., McHale \& Pawletko, 1992). Reiss et al. (1995), for example, showed that lower levels of parental support and monitoring and higher levels of parental negativity directed uniquely to one sibling predicted higher levels of depressive symptoms and antisocial behavior in that adolescent. Similarly, Mekos et al. (1996) demonstrated that differential treatment was more strongly related to problem behavior in remarried families where siblings did not share the same biological parent (for an evolutionary psychology perspective on stepparenthood, see Daly \& Wilson, 1996).

To conclude, any comprehensive theory of parental investment and its impact on children's development ultimately rests on insights from multiple disciplines. ${ }^{12}$ Such a theory should take into account crucial developmental insights and model the complex nature of parental investment that is likely to be shaped by a myriad of factors such as paternal uncertainty, parents' experience and values, and children's temperament. The modest contribution of our own analysis to such an integrative view is the observation that differential parental treatment and its effects on the children's development is a sufficient, but by no means a necessary, condition for differential outcomes: The very attempt by parents to treat children equally may, counterintuitively, lead to differential treatment, and ultimately to differential development.

\footnotetext{
${ }^{11}$ As Neiderhiser et al. (1999) have stressed, the family ecology variable parental treatment may itself be driven by genetically influenced characteristics of the child. Thus, an irritable and difficult-to-soothe child may elicit a more withdrawn and negative parenting style. Such a parenting style, if continued, may in turn contribute to adolescent maladjustment.

${ }^{12}$ We regret that we seem to be remote from such a comprehensive perspective as is, for instance, illustrated by the observations that textbooks in developmental psychology provide little to no reference to the existing parental investment literature. We searched the subject index of several recent textbooks of developmental psychology (Berger, 2000; Berk, 2000; Cole \& Cole, 1993; Santrock, 2002) and did not find a single mentioning of key words such as parental investment or parental resources. Similarly, we found only one reference to Trivers (1972); Hamilton was not mentioned at all.
}

\section{References}

Angelillo, I. F., Ricciardi, G., Rossi, P., Pantisano, P., Langiano, E., \& Pavia, M. (1999). Mothers and vaccination: Knowledge, attitude, and behavior in Italy. Bulletin of the World Health Organization, 77, 224 229.

Ballweg, J. A., \& Pagtolun-An, I. G. (1992). Parental underinvestment: A link in the fertility-mortality continuum. Population Research and Policy Review, 11, 73-89.

Barreto, T. V., \& Rodrigues, L. C. (1992). Factors influencing childhood immunization in an urban area of Brazil. Journal of Epidemiology and Community Health, 46, 357-361.

Becker, G. S. (1991). A treatise on the family. Cambridge, MA: Harvard University Press.

Becker, G. S., \& Tomes, N. (1976). Child endowments and the quantity and quality of children. Journal of Political Economy, 84, 143-162.

Becker, G. S., \& Tomes, N. (1986). Human capital and the rise and fall of families. Journal of Labor Economics, 4, 1-39.

Behrman, J. B., \& Taubman, P. (1986). Birth order, schooling, and earnings. Journal of Labor Economics, 4, 121-145.

Berger, K. S. (2000). The developing person: Through childhood and adolescence. New York: Worth.

Berk, L. E. (2000). Child development (5th ed.). Boston: Allyn \& Bacon.

Blake, J. (1981). Family size and the quality of children. Demography, 18, 421-442.

Blake, J. (1989). Family size and achievement. Los Angeles: University of California Press.

Boone, J. L., \& Kessler, K. L. (1999). More status or more children? Social status, fertility reduction, and long-term fitness. Evolution and Human Behavior, 20, 257-277. 
Borgerhoff Mulder, M. (1998). Brothers and sisters: How sibling interactions affect optimal parental allocations. Human Nature, 9, 119-162.

Bowlby, J. (1988). Parent-child attachment and healthy human development. New York: Basic Books.

Brittain, A. W. (1992). The effect of parental age, birth order and other variables on early childhood mortality: A Caribbean example. Social Science \& Medicine, 35, 1259-1271.

Brody, G. H., \& Stoneman, Z. (1994). Sibling relationships and their association with parental differential treatment. In E. M. Hetherington, D. Reiss, \& R. Plomin (Eds.), Separate social worlds of siblings: The impact of nonshared environment on development (pp. 129-142). Hillsdale, NJ: Erlbaum.

Brody, G. H., Stoneman, Z., \& Burke, M. (1987). Child temperaments, maternal differential behavior, and sibling relationships. Developmental Psychology, 23, 354-362.

Caldwell, B. M., \& Bradley, R. H. (1984). Manual for the home observation for measurement of the environment (Rev. ed.). Little Rock: University of Arkansas.

Chao, M. (2001). The birth-order controversy: Within-family effects and their generalizability. Unpublished honors thesis, University of California, Berkeley.

Chase, V. M., Hertwig, R., \& Gigerenzer, G. (1998). Visions of rationality. Trends in Cognitive Sciences, 2, 206-214.

Clutton-Brock, T. H. (1991). The evolution of parental care. Princeton, NJ: Princeton University Press.

Cole, M., \& Cole, S. R. (1993). The development of children (2nd ed.). New York: Scientific American Library.

Costa, P. T., Jr., \& McCrae, R. R. (1992). NEO PI-R professional manual. Odessa, FL: Psychological Assessment Resources.

Daly, M., \& Wilson, M. I. (1988). The Darwinian psychology of discriminative parental solicitude. In D. W. Leger (Ed.), Nebraska Symposium on Motivation: Vol. 35. Comparative perspectives in modern psychology (pp. 91-144). Lincoln: University of Nebraska Press.

Daly M., \& Wilson, M. I. (1996). Violence against stepchildren. Current Directions in Psychological Science, 5, 77-81.

Daniels, D., Dunn, J., Furstenberg, F. F., \& Plomin, R. (1985). Environmental differences within the family and adjustment differences within pairs of siblings. Child Development, 56, 764-774.

Daniels, D., \& Plomin, R. (1985). Differential experiences of siblings in the same family. Developmental Psychology, 21, 747-760.

Davie, R., Butler, N., \& Goldstein, H. (1972). From birth to seven: The second report of the national child development study (1958 cohort) with full statistical appendix. London: Longman.

Davis, J. N. (1997). Birth order, sibship size, and status in modern Canada. Human Nature, 8, 205-230.

Davis, J. N., \& Todd, P. M. (1999). Parental investment by decision rules. In G. Gigerenzer, P. M. Todd, \& the ABC Research Group, Simple heuristics that make us smart (pp. 309-324). New York: Oxford University Press.

Davis, J. N., Todd, P. M., \& Bullock, S. (1999). Environment quality predicts parental provisioning decisions. Proceedings of the Royal Society of London B, 266, 1791-1797.

Deutsch, M. (1975). Equity, equality, and need: What determines which value will be used as the basis of distributive justice? Journal of Social Issues, 31, 137-149.

Downey, D. B. (1995). When bigger is not better: Family size, parental resources, and children's educational performance. American Sociological Review, 60, 746-761.

Downey, D. B. (2001). Number of siblings and intellectual development: The resource dilution explanation. American Psychologist, 56, 497-504.

Dunn, J. F., \& McGuire, S. (1994). Young children's nonshared experiences: A summary of studies in Cambridge and Colorado. In E. M. Hetherington, D. Reiss, \& R. Plomin (Eds.), Separate social worlds of siblings: The impact of nonshared environment on development (pp. 111-128). Hillsdale, NJ: Erlbaum.

Dunn, J. F., \& Plomin, R. (1986). Determinants of maternal behavior toward three-year-old siblings. British Journal of Developmental Psychology, 4, 127-137.

Dunn, J. F., Plomin, R., \& Daniels, D. (1986). Consistency and change in mothers' behavior toward young siblings. Child Development, 57, 348 356.

Dunn, J. F., Plomin, R., \& Nettles, M. (1985). Consistency of mothers' behavior toward infant siblings. Developmental Psychology, 21, 11881195.

Elder, G. H., Jr. (1974). Children of the Great Depression: Social change in life experience. Chicago: University of Chicago Press.

Elder, G. H., Jr. (1998). The life course as developmental theory. Child Development, 69, 1-12.

Elster, J. (1997). More than enough. The University of Chicago Law Review, 64, 749-764.

Erikson, E. H. (1968). Identity: Youth and crisis. New York: Norton.

Ernst, C., \& Angst, J. (1983). Birth order: Its influence on personality. Berlin, Germany: Springer Verlag.

Frank, S. A. (1990). Sex allocation theory for birds and mammals. Annual Review of Ecology and Systematics, 21, 13-55.

Geary, D. C. (2000). Evolution and proximate expression of human paternal investment. Psychological Bulletin, 126, 55-77.

Geary, D. C., \& Flinn, M. V. (2001). Evolution of human parental behavior and the human family. Parenting: Science and Practice, 1, 5-61.

Gigerenzer, G., Todd, P. M., \& the ABC Research Group. (1999). Simple heuristics that make us smart. New York: Oxford University Press.

Goldstein, H. (1971). Factors influencing the height of seven year old children—results from the National Child Development Study. Human Biology, 43, 92-111.

Griffore, R. J., \& Bianchi, L. (1984). Effects of ordinal position on academic self-concept. Psychological Reports, 55, 263-268.

Hamilton, W. D. (1964a). The genetical evolution of social behavior. I. Journal of Theoretical Biology, 7, 1-16.

Hamilton, W. D. (1964b). The genetical evolution of social behavior. II. Journal of Theoretical Biology, 7, 17-32.

Hanushek, E. A. (1992). The trade-off between child quantity and quality. Journal of Political Economy, 100, 84-117.

Heer, D. M. (1985). Effects of sibling number on child outcome. Annual Review of Sociology, 11, 27-47.

Heer, D. M. (1986). Effect of number, order, and spacing of siblings on child and adult outcomes: An overview of current research. Social Biology, 33, 1-4.

Herlihy, D. (1973). Three patterns of social mobility in medieval history. Journal of Interdisciplinary History, 3, 622-647.

Hill, C. R., \& Stafford, F. P. (1974). Allocation of time to preschool children and educational opportunity. The Journal of Human Resources, 9, 323-341.

Hill, C. R., \& Stafford, F. P. (1980). Parental care of children: Time diary estimates of quantity, predictability, and variety. The Journal of Human Resources, 15, 219-239.

Hill, K., \& Hurtado, M. (1996). Ache life history: The ecology and demography of a foraging people. New York: Aldine De Gruyter.

Horton, S. (1988). Birth order and child nutritional status: Evidence from the Philippines. Economic Development and Cultural Change, 36, 341354.

Hrdy, S. B. (1999). Mother nature: A history of mothers, infants, and natural selection. New York: Pantheon Books.

Huttenlocher, P. R. (1994). Synaptogenesis in human cerebral cortex. In G. Dawson \& K. W. Fischer (Eds.), Human behavior and the developing brain (pp. 35-54). New York: Guilford Press.

Ivey, P. K. (2000). Cooperative reproduction in Ituri Forest hunter-gatherers: Who cares for Efe infants? Current Anthropology, 41, 856-866. 
Kagan, J. (1987). Perspectives on infancy. In J. D. Osofsky (Ed.), Handbook on infant development (2nd ed., pp. 1150-1198). Oxford, England: Wiley.

Kaplan, B. A., Mascie-Taylor, C. G. N., \& Boldsen, J. (1992). Birth order and health status in a British national sample. Journal of Biosocial Science, 24, 25-33.

Kaplan, H., Hill, K., Lancaster, J. B., \& Hurtado, A. M. (2000). A theory of human life history evolution: Diet, intelligence, and longevity. Evolutionary Anthropology, 9, 156-185.

Kaplan, H., Lancaster, J. B., \& Anderson, K. G. (1998). Human parental investment and fertility: The life histories of men in Albuquerque. In A. Booth \& N. Crouter (Eds.), Men in families: When do they get involved? What difference does it make? (pp. 55-111). New York: Erlbaum.

Kennedy, G. E. (1989). Middleborns' perceptions of family relationships. Psychological Reports, 64, 755-760.

Kidwell, J. S. (1981). Number of siblings, sibling spacing, sex, and birth order: Their effects on perceived parent-adolescent relationships. Journal of Marriage and the Family, 43, 315-332.

Kidwell, J. S. (1982). The neglected birth order: Middleborns. Journal of Marriage and the Family, 44, 225-235.

Koch, H. L. (1960). The relation of certain formal attributes of siblings to attitudes held toward each other and toward their parents. Monographs of the Society for Research in Child Development, 24(4, Whole No. 78) 134.

Kuo, H.-H. D., \& Hauser, R. M. (1996). Gender, family configuration, and the effect of family background on educational attainment. Social Biology, 43, 98-131.

Lee, R. B. (1979). The Kung San: Men, women and work in a foraging society. Cambridge, England: Cambridge University Press.

Leibowitz, A. (1974a). Education and home production. American Economic Review, 64, 243-250.

Leibowitz, A. (1974b). Home investments in children. Journal of Political Economy, 82, 111-131.

Leibowitz, A. (1977). Parental inputs and children's achievement. The Journal of Human Resources, 12, 242-251.

Lewis, S. A., \& Britton, J. R. (1998). Measles infection, measles vaccination and the effect of birth order in the aetiology of hay fever. Clinical and Experimental Allergy, 28, 1493-1500.

Li, J., \& Taylor, B. (1993). Factors affecting uptake of measles, mumps, and rubella immunization. British Medical Journal, 307, 168-171.

Lindert, P. H. (1977). Sibling position and achievement. The Journal of Human Resources, 12, 198-219.

Lynch, K. A., \& Greenhouse, J. B. (1994). Risk factors for infant mortality in nineteenth-century Sweden. Population Studies, 48, 117-133.

Maccoby, E. E., \& Martin, U. A. (1983). Socialization in the context of the family: Parent-child interaction. In P. H. Mussen \& E. M. Hetherington (Eds.), Handbook of child psychology: Vol. 4. Socialization, personality, and social development (4th. ed., pp. 1-110). New York: Wiley.

Marjoribanks, K. (1988). Sibling, family environment and ability correlates of adolescents' aspirations: Ethnic group differences. Journal of Biosocial Science, 20, 203-209.

Marjoribanks, K. (1989). Ethnicity, sibling, and family correlates of young adults' status attainment: A follow-up study. Social Biology, 36, 23-31.

Marjoribanks, K. (1991). The sibling resource dilution theory: An analysis. The Journal of Psychology, 125, 337-346.

McCrae, R. R., \& Costa, P. T., Jr. (1987). Validation of the five-factor model of personality across instruments and observers. Journal of Personality and Social Psychology, 52, 81-90.

McGinley, M. A., \& Charnov, E. L. (1988). Multiple resources and the optimal balance between size and number of offspring. Evolutionary Ecology, 2, 77-84.

McHale, S. M., \& Pawletko, T. M. (1992). Differential treatment of siblings in two family contexts. Child Development, 63, 68-81.

Mekos, D., Hetherington, E. M., \& Reiss, D. (1996). Sibling differences in problem behavior and parental treatment in nondivorced and remarried families. Child Development, 67, 2148-2165.

Messick, D. M. (1993). Equality as a decision heuristic. In B. A. Mellers \& J. Baron (Eds.), Psychological perspectives on justice: Theory and applications (pp. 11-31). New York: Cambridge University Press.

Messick, D. M., \& Schell, T. (1992). Evidence for an equality heuristic in social decision making. Acta Psychologica, 80, 311-323.

Modin, B. (2002). Birth order and mortality: A life-long follow-up of 14,200 boys and girls born in early 20th century Sweden. Social Science \& Medicine, 54, 1051-1064.

Neiderhiser, J. M., Reiss, D., Hetherington, E. M., \& Plomin, R. (1999). Relationships between parenting and adolescent adjustment over time: Genetic and environmental contributions. Developmental Psychology, 35, 680-692.

Ohtsubo, Y., \& Kameda, T. (1998). The function of equality heuristic in distributive bargaining: Negotiated allocation of costs and benefits in a demand revelation context. Journal of Experimental Social Psychology, 34, 90-108.

Page, E. B., \& Grandon, G. M. (1979). Family configuration and mental ability: Two theories contrasted with U.S. data. American Educational Research Journal, 16, 257-272.

Paulhus, D. L., Trapnell, P. D., \& Chen, D. (1999). Birth order effects on personality and achievement within families. Psychological Science, 10, 482-488.

Payne, J. W., Bettman, J. R., \& Johnson, E. J. (1993). The adaptive decision maker. New York: Cambridge University Press.

Plomin, R., \& Daniels, D. (1987). Why are children in the same family so different from one another? Behavioral and Brain Sciences, 10, 1-16.

Powell, B., \& Steelman, L. C. (1989). The liability of having brothers: Paying for college and the sex composition of the family. Sociology of Education, 62, 134-147.

Powell, B., \& Steelman, L. C. (1993). The educational benefits of being spaced out: Sibship density and educational progress. American Sociological Review, 58, 367-381.

Price, J. (1969). Personality differences within families: Comparisons of adult brothers and sisters. Journal of Biosocial Science, 1, 117-205.

Reiss, D., Hetherington, E. M., Plomin, R., Howe, G., Simmens, S., Henderson, S. H., et al. (1995). Genetic questions for environmental studies: Differential parenting of siblings and its association with depression and antisocial behavior in adolescents. Archives of General Psychiatry, 52, 925-936.

Richter, J., Richter, G., Eisemann, M., \& Mau, R. (1997). Sibship size, sibship position, parental rearing, and psychopathological manifestations in adults: Preliminary analysis. Psychopathology, 30, 155-162.

Rodgers, J. L. (2001). What causes birth order-intelligence patterns?: The admixture hypothesis, revised. American Psychologist, 56, 505-510.

Rodgers, J. L., Cleveland, H. H., van den Oord, E., \& Rowe, D. C. (2000). Resolving the debate over birth order, family size, and intelligence. American Psychologist, 55, 599-612.

Rohde, P. A., Andres, A. A., Atzwanger, K., Butovskaya, M., Lampert, A., Mysterud, L., \& Sulloway, F. J. (2002). Perceived parental favoritism, closeness to kin, and the rebel of the family: The effects of birth order and sex. Unpublished manuscript.

Rosenheim, J. A., Nonacs, P., \& Mangel, M. (1996). Sex ratios and multifaceted parental investment. American Naturalist, 148, 501-535.

Salmon, C. A. (1998). The evocative nature of kin terminology in political rhetoric. Politics and the Life Sciences, 17, 51-57.

Salmon, C. A. (1999). On the impact of sex and birth order on contact with kin. Human Nature, 10, 183-197.

Salmon, C. A., \& Daly, M. (1998). Birth order and familial sentiment: Middleborns are different. Evolution and Human Behavior, 19, 299312 .

Santrock, J. W. (2002). Life-span development (8th ed.). Boston: McGrawHill. 
Schachter, F. F., Gilutz, G., Shore, E., \& Adler, M. (1978). Sibling deidentification judged by mothers: Cross-validation and developmental studies. Child Development, 49, 543-546.

Scheper-Hughes, N. (1992). Death without weeping: The violence of everyday life in Brazil. Berkeley: University of California Press.

Schneider, B. H., Atkinson, L., \& Tardif, C. (2001). Child-parent attachment and children's peer relations: A quantitative review. Developmental Psychology, 37, 86-100.

Schooler, C. (1972). Birth order effects: Not here, not now! Psychological Bulletin, 78, 161-175.

Scrimshaw, S. C. M. (1978). Infant mortality and behavior in the regulation of family size. Population and Developmental Review, 4, 383-403.

Scrimshaw, S. C. M. (1984). Infanticide in human populations. In G. Hausfater \& S. B. Hrdy (Eds.), Infanticide: Comparative and evolutionary perspectives (pp. 439-462). New York: Aldine.

Simpson, J. A., \& Weiner, E. S. C. (Eds.). (1989). The Oxford English dictionary (2nd ed., Vol. 5). Oxford, England: Clarendon Press.

Skinner, W. G. (1992). Seek a loyal subject in a filial son: Family roots of political orientation in Chinese society. In Institute of Modern History, Academia Sinica (Ed.), Family process and political process in modern Chinese history (pp. 943-993). Taipei, People's Republic of China: Academia Sinica.

Steelman, L. C. (1985). A tale of two variables: The intellectual consequences of sibship size and birth order. Review of Educational Research, 55, 353-386.

Steelman, L. C., \& Powell, B. (1989). Acquiring capital for college: The constraints of family configuration. American Sociological Review, 54, $844-855$.

Sulloway, F. J. (1996). Born to rebel: Birth order, family dynamics, and creative lives. New York: Pantheon Books.

Sulloway, F. J. (1999). Birth order. In M. A. Runco \& S. R. Pritzken (Eds.), Encyclopedia of creativity (Vol. 1, pp. 189-202). San Diego, CA: Academic Press.
Sulloway, F. J. (2001a). Birth order, sibling competition, and human behavior. In H. R. Holcomb III (Ed.), Conceptual challenges in evolutionary psychology: Innovative research strategies (pp. 39-83). Dordrecht, the Netherlands: Kluwer Academic.

Sulloway, F. J. (2001b). Study on birth order and personality. Unpublished data.

Taubman, P., \& Behrman, J. B. (1986). Effect of number and position of siblings on child and adult outcomes. Social Biology, 33, 22-34.

Travis, R., \& Kohli, V. (1995). The birth order factor: Ordinal position, social strata, and educational achievement. Journal of Social Psychology, 135, 499-507.

Trivers, R. L. (1972). Parental investment and sexual selection. In B. Campbell (Ed.), Sexual selection and the descent of man: 1871-1971 (pp. 136-179). Chicago: Aldine.

Trivers, R. (1974). Parent-offspring conflict. American Zoologist, 14, $249-264$.

Vandell, D. L., \& Beckwith, S. (1989, April). Maternal styles of interaction with infant twins. Paper presented at the meeting of the Society for Research in Child Development, Kansas City, MO.

Zajonc, R. B. (2001). The family dynamic of intellectual development. American Psychologist, 56, 490-496.

Zajonc, R. B., \& Markus, G. B. (1975). Birth order and intellectual development. Psychological Review, 82, 74-88.

Zajonc, R. B., Markus, H., \& Markus, G. B. (1979). The birth order puzzle. Journal of Personality and Social Psychology, 37, 1325-1341.

Zervas, L. J., \& Sherman, M. F. (1994). The relationship between perceived parental favoritism and self-esteem. The Journal of Genetic Psychology, 155, 25-33.

Received March 8, 2001

Revision received March 5, 2002

Accepted March 8, 2002

\section{Low Publication Prices for APA Members and Affiliates}

Keeping you up-to-date. All APA Fellows, Members, Associates, and Student Affiliates receive-as part of their annual dues-subscriptions to the American Psychologist and APA Monitor. High School Teacher and International Affiliates receive subscriptions to the APA Monitor, and they may subscribe to the American Psychologist at a significantly reduced rate. In addition, all Members and Student Affiliates are eligible for savings of up to $60 \%$ (plus a journal credit) on all other APA journals, as well as significant discounts on subscriptions from cooperating societies and publishers (e.g., the American Association for Counseling and Development, Academic Press, and Human Sciences Press).

Essential resources. APA members and affiliates receive special rates for purchases of APA books, including the Publication Manual of the American Psychological Association, and on dozens of new topical books each year.

Other benefits of membership. Membership in APA also provides eligibility for competitive insurance plans, continuing education programs, reduced APA convention fees, and specialty divisions.

More information. Write to American Psychological Association, Membership Services, 750 First Street, NE, Washington, DC 20002-4242. 